\title{
TAMANHO E NÚMERO DE PARCELAS PARA AMOSTRAGEM DO ESTRATO ARBÓREO NUM TRECHO DE FLORESTA SECUNDÁRIA DO PARQUE ESTADUAL DE CARLOS BOTELHO (SP)
}

Dissertação apresentada à Escola Superior de Agricultura "Luiz de Queiroz", Universidade de São Paulo, para obtenção do título de Mestre em Ciências, Área de Concentração Ciências Florestais. 
Dados Internacionais de Catalogaçāo na Publicação (CIP) DIVISÃO DE BIBLIOTECA E DOCUMENTAÇĀO - Campus "Luiz de Queiroz"/USP

\author{
Vieira, Maria Gláucia Legaspe \\ Tamanho e número de parcelas para amostragem do estrato arbóreo num trecho \\ de floresta secundária do Parque Estadual de Carlos Botelho / Maria Gláucia Legaspe \\ Vieira. - - Piracicaba, 1997. \\ 69 p. : il. \\ Dissertação (mestrado) - - Escola Superior de Agricultura Luiz de Queiroz, 1999. \\ Bibliografia. \\ 1. Espécie florestal 2. Floresta secundária 3. Parque Estadual de Carlos Botelho, \\ SP I. Titulo
}

CDD 634.94

SPermitida a copla total ou parcul deste documento, desde que citada a fonte o Autor? 
TAMANHO E NÚMERO DE PARCELAS PARA AMOSTRAGEM DO ESTRATO ARBÓREO NUM TRECHO DE FLORESTA SECUNDÁRIA DO PARQUE ESTADUAL DE CARLOS BOTELHO (SP)

\section{MARIA GLÁUCIA LEGASPE VIEIRA}

Aprovada em: 09/03/1998

Comissão Julgadora:

Prof. Dr. Hilton Thadeu Z. do Couto

ESALQ/USP

Prof. Dr. João Luís Ferreira Batista

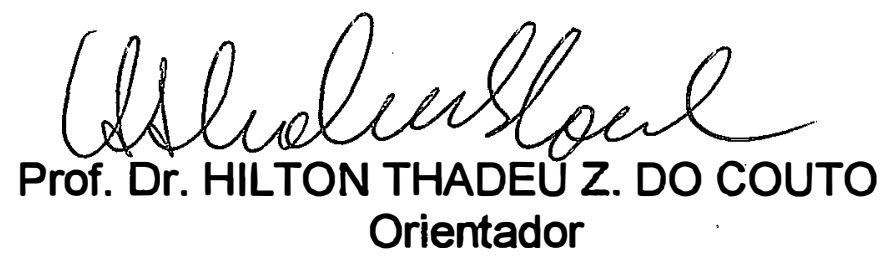


Dedico ao Osmar 


\section{AGRADECIMENTOS}

Sinceros agradecimentos ao Instituto Florestal de São Paulo.

Ao orientador, Prof. Dr. Hilton Thadeu Z. do Couto, quero expressar minha gratidão pela orientação, apoio e incentivo em todos os momentos e circunstâncias, ao longo de todo esse processo e pela amizade firmada.

Aos colegas e amigos da Divisão de Dasonomia pelo apoio a mim dispensado. Aos colegas e amigos da Estação Experimental de Tupi pela acolhida e por tudo que me proporcionaram.

Aos colegas e amigos da pós-graduação pelo caminho que percorremos juntos. Ao Samir, colega da pós, grande amigo, um agradecimento especial, pela dedicação, empenho, desprendimento, não medindo esforços em contribuir em todas as fases deste trabalho. Aos professores e funcionários do Departamento de Ciências Florestais e do IPEF, particularmente à Marialice e ao Paulo.

Ao pesquisador Bento Vieira de Moura Netto, chefe do P. E. de Carlos Botelho, e aos demais funcionários, especialmente, aos senhores: Pedro Osório, Clarindo, Marcos Antônio, Miguel Pedro, Natanael, Enedino, Waldomiro e João Muniz pelo auxílio que me prestaram nos trabalhos de campo.

Aos pesquisadores Edegar Giannotti e João Batista Baitello e ao Prof. João L. F. Batista pelas sugestões apresentadas.

Aos meus familiares que me compreenderam e me ajudaram.

À CAPES pelo auxílio financeiro.

À todos que direta ou indiretamente me auxiliaram com a compreensão, a paciência e o incentivo. 


\section{SUMÁRIO}

LISTA DE FIGURAS …........................................................ vi

LISTA DE TABELAS .............................................................viii

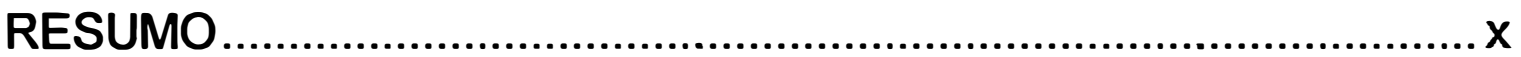

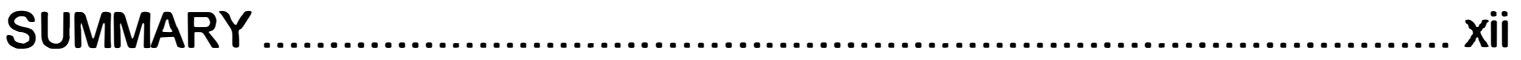

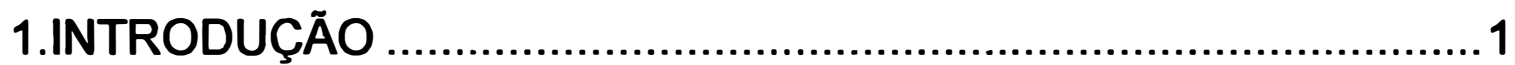

2. REVISÃO BIBLIOGRÁFICA ................................................. 3

2.1 A Floresta Atlântica.................................................... 3

2.2 Amostragem de Florestas Tropicais ..................................5

3. MATERIAIS E MÉTODOS .................................................. 12

3.1. Características do Local .................................................. 12

3.2 Procedimento no Campo ............................................... 14

3.2.1 Seleção da área do estudo ........................................ 14

3.2.2 Amostragem......................................................... 14

3.3 Procedimento no laboratório.............................................. 15

3.3.1 Cálculo dos parâmetros fitossociológicos .....................16

3.3.2 Método do coeficiente de correlação intraclasse ..............18

4. RESULTADOS E DISCUSSÃO .........................................21

4.1 Fitossociologia ............................................................ 21

4.1.1 As Espécies e seus Parâmetros Fitossociológicos..........25

4.1.2 Árvores Mortas ......................................................... 34

4.1.3 Classes de IVI ....................................................... 35

4.1.4 Diversidade e Equabilidade .......................................37

4.1.5 Classes de Diâmetros ................................................ 38

4.2 Tamanho e número de parcelas .......................................47

4.2.1 Estimativas para a floresta a partir da área basal e da densidade.

4.2.2 Estimativas para algumas espécies a partir da densidade51 5. CONCLUSÃO 


\section{LISTA DE FIGURAS}

FIGURA 1 - Localização do Parque Estadual de Carlos Botelho, SP...... 13

FIGURA 2 - IVI das 15 espécies mais importantes em uma mata secundária no Parque Estadual de Carlos Botelho, SP..........................28

FIGURA 3 - IVC das 15 espécies com maiores valores e a participação da dominância e densidade relativas em uma mata secundária no Parque Estadual de Carlos Botelho, SP

FIGURA 4 - As 15 espécies com maiores dominâncias em uma mata secundária no Parque Estadual de Carlos Botelho, SP. 30

FIGURA 5 - As 15 espécies com maiores densidades em uma mata secundária no Parque Estadual de Carlos Botelho, SP

FIGURA 6 - As 15 espécies com maiores freqüências em uma mata secundária no Parque Estadual de Carlos Botelho, SP. 31

FIGURA 7 - Porcentagens de dominância, densidade e freqüência relativas na composição do IVI dentre as 15 mais importantes em uma mata secundária no Parque Estadual de Carlos Botelho, SP.

FIGURA 8 - Distribuição diamétrica de Ocotea sp em uma mata secundária no Parque Estadual de Carlos Botelho, SP.

FIGURA 9 - Distribuição diamétrica de Tibouchina pulchra em uma mata secundária no Parque Estadual de Carlos Botelho, SP. 40

FIGURA 10 - Distribuição diamétrica de Rapanea fermuginea em uma mata secundária no Parque Estadual de Carlos Botelho, SP.

FIGURA 11 - Distribuição diamétrica de Solanum inaequale em uma mata secundária no Parque Estadual de Carlos Botelho, SP.

FIGURA 12 - Distribuição diamétrica de árvores mortas em uma mata secundária no Parque Estadual de Carlos Botelho, SP. 
FIGURA 13 - Distribuição diamétrica de Psychotria sp2. em uma mata secundária no Parque Estadual de Carlos Botelho, SP.

FIGURA 14 - Distribuição diamétrica de Guatteria sp. em uma mata secundária no Parque Estadual de Carlos Botelho, SP. 43

FIGURA 15 - Distribuição diamétrica de Cabralea canjerana em uma mata secundária no Parque Estadual de Carlos Botelho, SP. 44

FIGURA 16 - Distribuição diamétrica de Jacaranda puberula em uma mata secundária no Parque Estadual de Carlos Botelho, SP.

FIGURA 17 - Distribuição diamétrica de Hyeronima alchomeoides em uma mata secundária no Parque Estadual de Carlos Botelho, SP.

FIGURA 18 - Distribuição diamétrica de Roupala brasiliensis em uma mata secundária no Parque Estadual de Carlos Botelho, SP.

FIGURA 19 - Distribuição diamétrica de Euterpe edulis em uma mata secundária no Parque Estadual de Carlos Botelho, SP. 


\section{LISTA DE TABELAS}

TABELA 1 - Composição florística de espécies arbóreas num trecho de mata secundária do Parque Estadual de Carlos Botelho.

TABELA 2 - Parâmetros fitossociológicos das espécies amostradas em ordem decrescente de IVI (Índice de Valor de Importância), onde Do=dominância absoluta; De=densidade absoluta; $\mathrm{Fr}=$ freqüência absoluta; IVC=Índice de Valor de Cobertura; DoR, DeR e FrR são os parâmetros relativos. 25

TABELA 3 - Distribuição do Número de Espécies e indivíduos em Classes de IVI. 35

TABELA 4 - Quadro de análise de variância para estimativa de $\rho$ a partir da área basal por subparcela $\left(\mathrm{m}^{2} /\right.$ subparcela de $\left.200 \mathrm{~m}^{2}\right)$. 48

TABELA 5 - Quadro de análise de variância para estimativa de $\rho$ a partir da densidade de árvores ( $\mathrm{n} / \mathrm{subparcela} \mathrm{de} 200 \mathrm{~m}^{2}$ ).

TABELA 6 - Estimativas de área basal $\left(\mathrm{m}^{2} / \mathrm{ha}\right)$ e densidade de árvores (n/ha) por subparcela numa mata secundária do Parque Estadual de Carlos Botelho (SP). 48

TABELA - 7 Tamanho e número de parcelas $\left(r^{\prime}\right)$ em função da área basal e densidade no Parque Estadual de Carlos Botelho (SP), para uma relação de custo $f=1$.

TABELA 8 - Estimativas do tamanho e número de parcelas para árvores mortas e algumas das principais espécies da área, para uma relação de custo $f=1$. . 52

TABELA 9 - Distribuição esquemática de individuos de Rapanea ferruginea. .53

TABELA 10 - Distribuição esquemática de indivíduos de Roupala brasiliensis.

TABELA 11 - Distribuição esquemática de indivíduos de Tibouchina pulchra. 
TABELA 12 - Distribuição esquemática de indivíduos de árvores Mortas. TABELA 13 - Distribuição esquemática de individuos de Hyeronima alchorneoides. 55

TABELA 14 - Distribuição esquemática de indivíduos de Solanum inaequale. 55

TABELA 15 - Distribuição esquemática de indivíduos de Cabralea canjerana. 56

TABELA 16 - Distribuição esquemática de individuos de Euterpe edulis. 56

TABELA 17 - Distribuição esquemática de indivíduos de Jacaranda puberula. 


\section{TAMANHO E NÚMERO DE PARCELAS PARA ÁMOSTRAGEM DO ESTRATO ARBÓREO NUM TRECHO DE FLORESTA SECUNDÁRIA DO PARQUE ESTADUAL DE CARLOS BOTELHO} (SP)

\section{Autor: MARIA GLÁUCIA LEGASPE VIEIRA Orientador: Dr. HILTON THADEU Z. DO COUTO}

\section{RESUMO}

Este trabalho aborda o tamanho e número de parcelas para amostragem da Floresta Atlântica, levando em conta o coeficiente de correlação intraclasse ( $\rho$ ) entre subparcelas dentro de parcelas, com base na fitossociologia da vegetação arbórea de um trecho de mata secundária, no Parque Estadual de Carlos Botelho, localizado na região sul do estado de São Paulo, nas coordenadas geográficas $24^{\circ} 00^{\prime}$ a $24^{\circ}$ $15^{\prime}$ de Latitude Sul e $47^{\circ} 45^{\prime}$ a $48^{\circ} 10^{\prime}$ de Longitude Oeste.

A amostragem em campo constou de 5 parcelas de $10 \times 200$ m, subdivididas em 10 subparcelas de $10 \times 20$ m, sendo amostrados todos os indivíduos com DAP $\geq 5 \mathrm{~cm}$. Os 1685 individuos amostrados distribuem-se entre 105 espécies, 65 gêneros e 34 famílias. As famílias com maior riqueza em espécies foram Leguminosae, Myrtaceae, Lauraceae, Rubiaceae e Euphorbiaceae. O índice de diversidade de Shannon foi de 3,66. O tamanho de parcelas mais adequado para se amostrar a densidade de árvores nesta floresta foi de $10 \times 60 \mathrm{~m}$, 
baseando-se no desenho amostral inicial. Para as principais espécies, detectadas pela análise fitossociológica o tamanho e número de parcelas variou amplamente. Por exemplo para se amostrar a densidade de Hyeronima alchomeoides seriam necessárias 17 parcelas de $10 \times 40 \mathrm{~m}$. Já para Tibouchina pulchra seriam necessárias 3 parcelas de $10 \times 320 \mathrm{~m}$. Isso mostra que ao admitir-se um tamanho único de parcelas para a amostragem da comunidade florestal, erros de grande proporção podem estar sendo envolvidos quando se extrapolam as estimativas a nivel de espécies. 


\section{SIZE AND NUMBER OF PLOTS FOR SAMPLING OF THE TREE VEGETATION IN A PART OF SECONDARY FOREST OF THE STATE PARK OF "CARLOS BOTELHO" (SP).}

\section{Author: MARIA GLÁUCIA LEGASPE VIEIRA}

Adviser: Dr. HILTON THADEU Z. DO COUTO

\section{SUMMARY}

This work deals with the size and the number of plots for sampling of the Atlantic forest, taking in account the intra-class coeficient of correlation ( $\rho$ ) among sub-plots within plots, based on the phytossociology of the tree vegetation in a part of secondary forest in the "Parque Estadual de Carlos Botelho", located in the south region of the State of São Paulo, Brazil $\left(24^{\circ} 00^{\prime}-24^{\circ} 15^{\prime} \mathrm{SL}\right.$ and $\left.47^{\circ} 45^{\prime}-48^{\circ} 10^{\prime} \mathrm{W}\right)$. The study area consisted of 5 plots of $10 \times 200 \mathrm{~m}$, subdivided by 10 subplots of $10 \times 20 \mathrm{~m}$, every trees with $\mathrm{DBH} \geq 5 \mathrm{~cm}$ were measured, totalizing 1685 trees. The families with the major number of species were: Leguminosae, Myrtaceae, Lauraceae, Rubiaceae and Euphorbiaceae. The diversity index of Shannon was $H^{\prime}=3,66$. The size of the plot more adequated to estimate the density of trees in this area was of $10 \times 60 \mathrm{~m}$, based on the inicial design. For some of the main species in this area, the size and number of the plots were variabled in according to its density, like: 17 plots of $10 \times 40 \mathrm{~m}$ to Hyeronima alchomeoides and 3 plots of $10 \times$ 320 to Tibouchina pulchra. 


\section{INTRODUÇÃO}

O processo desenvolvimentista que, historicamente, caracterizou São Paulo, acarretou, concomitantemente, a devastação de sua cobertura florestal, na busca de terras férteis para implantação da agricultura, com as frentes de expansão colonizadora e, posteriormente, com a urbanização e a industrialização que acentuaram esse processo.

O remanescente da cobertura florestal nativa do estado de São Paulo encontra-se restrito, praticamente, à formação atlântica com predominância na faixa litorânea e vale do Ribeira e trechos esparsos de floresta mesófila, além de cerrado e cerradão, na região interiorana.

O Plano de Ação Emergencial (Costa Neto, 1993/94) salienta a relevância do ecossistema mata atlântica em nivel nacional, do qual restam aproximadamente $3 \%$ da área original.

A Política Ambiental Global para a Mata Atlântica (Fundação SOS/Mata Atlântica, 1992) propõe, entre outros aspectos abordados, o desenvolvimento de estudos e pesquisas científicas sobre flora, dinâmica dos ecossistemas, genética das populações, efeitos da fragmentação e redução dos habitats e técnicas para regeneração e recuperação de áreas degradadas, visando aprofundar o conhecimento da região.

Embora haja inúmeros estudos enfocando a vegetação nativa a questão da amostragem para avaliar uma comunidade vegetal, ainda constitui problema. Vale ressaltar que pela amostragem é possivel medir parte de uma população e inferir sobre sua totalidade. A amostra deve ser representativa da população a ser estudada, levando a estimativas mais precisas. 
Desta forma, estabelecer amostras toma-se problemático, principalmente em florestas tropicais, devido à heterogeneidade florística e ao caráter multiâneo dessas florestas.

Neste sentido este trabalho tem por objetivos:

1. Descrever a estrutura de uma floresta secundária do Parque Estadual de Carlos Botelho (SP);

2. Analisar o tamanho e número de parcelas na floresta, bem como de algumas de suas principais espécies, buscando verificar quais as possiveis variações no tamanho e número de parcelas que se podem obter em função das diferentes espécies arbóreas; 


\section{REVISÃO BIBLIOGRÁFICA}

\subsection{A Floresta Atlântica}

Primitivamente, a cobertura florestal do estado de São Paulo atingia $82 \%$ de seu território (Victor, 1975), reduzida a $8,33 \%$ no período 71 a 73 (Serra Filho et al., 1974), atualmente, abrange somente 5\% (CONSEMA,1985). Historicamente, a devastação da cobertura florestal do estado vincula-se ao seu desenvolvimento econômico iniciando-se com o surto cafeeiro e, posteriormente, com o avanço das ferrovias, a diversificação da agricultura e a industrialização.

A maior concentração da cobertura florestal remanescente no estado encontra-se na encosta atlântica e vale do Ribeira (Serra Filho et al. 1974). As áreas remanescentes da cobertura vegetal natural no estado, conforme Kronka et al.(1993), situam-se em locais acidentados de difícil acesso, constituindo unidades de conservação ou áreas protegidas.

A mata atlântica, de acordo com Joly (1970), é resultante das condições climáticas especiais criadas pela barreira da serra do Mar e caracteriza-se pela grande diversidade de espécies. Hueck (1972) também acentua que sua existência deve-se à grande umidade do ar, trazida pelos ventos marítimos e se estende por uma larga faixa do Rio Grande do Norte para o sul. Em sua composição Joly (1970) cita como arvoretas algumas espécies de Coccoloba, Miconia e Bathysa e dentre as árvores menores, mais freqüentes: Inga, Affonsea e Ocotea. As árvores mais altas são representadas por Swartzia langsdorfii, Bombax wittrochianum e Alchomea triplinervia. Salienta, como as famílias mais freqüentes: Myrtaceae, Euphorbiaceae, Melastomataceae e Guttiferae. Ressalta, também a presença das palmeiras pequenas do gênero 
Geonoma e do palmito Euterpe edulis, em vários estádios de desenvolvimento, com altura atingindo $18-20 \mathrm{~m}$ e até mais.

Conforme Hueck (1972) entre as árvores estão bem representadas as leguminosas, bignoniáceas, sapotáceas, lauráceas, meliáceas e mirtáceas. As leguminosas apresentam maior número de espécies, com os gêneros Piptadenia, Hymenaea, Melanoxylon, Centrolobium, entre outros. Dentre as bignoniaceas destacam-se Jacaranda e Tabebuia. Largamente distribuídas encontram-se as lauráceas dos gêneros Ocotea e Nectandra, que não produzem madeira de valor comercial; importantes devido à madeira produzida, o destaque cabe aos gêneros Cabralea e Cedrela, da família Meliaceae.

Em estudo realizado no Parque Estadual de Carlos Botelho, Heinsdjk e Campos (1967) detectaram como as famílias mais freqüentes, em ordem decrescente: Myrtaceae, Leguminosae e Lauraceae. Assinalaram a ocorrência de mais de 25 espécies pertencentes à família Myrtaceae. O levantamento baseou-se nas árvores com DAP a partir de $25 \mathrm{~cm}$.

Em área amostrada no Núcleo Sete Barras do Parque Estadual de Carlos Botelho, considerando árvores a partir dos $15 \mathrm{~cm}$ de DAP, Negreiros (1982) detectou entre as essências de maior IVI: Bathysa sp., Euterpe edulis, Sloanea sp., Tetrastylidium sp., Grupo de espécies da familia Myrtaceae, Cryptocarya sp., Nectandra sp., Chrysophyllum sp., Hyeronima sp., Cupania sp., Cabralea sp., Inga sp. e Guapira sp.

Com referência às espécies arbóreas ocorrentes no Parque Estadual de Carlos Botelho, Custodio Filho et al. (1992) apresentam uma relação de 51 famílias e 176 espécies, aproximadamente, 3500 
indivíduos, com base em levantamentos quantitativos e fenológicos em andamento na região.

\subsection{Amostragem de Florestas Tropicais}

Para estudos de floresta tropical Heinsdijk e Campos (1967) acentuam a importância do sistema de amostragem a ser utilizado, levando em conta o tamanho da área para determinação do tipo ou tamanho da amostra.

Spurr (1952) pondera que quanto mais variável for a floresta, maior deverá ser a intensidade de amostragem. Hasel (1942), citado por Spurr (1952), trabalhando com dados da Califómia, conclui que a variância não aumenta proporcionalmente ao volume. Desta forma povoamentos com alto volume requereriam amostragem mais suave, do que povoamentos com baixo volume, para o mesmo grau relativo de precisão. Chama a atenção para o fato de que povoamentos de baixa densidade são, geralmente, mais variáveis e requerem mais amostragem para a mesma exatidão relativa do que povoamentos inteiramente estocados.

Negreiros (1982) assinala que para analisar uma comunidade florestal, com fins sociológicos, a forma da parcela para a amostragem é um problema que deve ser considerado. Com base em amostragem preliminar o referido autor determinou a área mínima para análise da vegetação, no Núcleo Sete Barras, Parque Estadual de Carlos Botelho, através de curvas espécie-área adotando superfície quadrada de $2500 \mathrm{~m}^{2}$ subdividida em 25 subparcelas de $100 \mathrm{~m}^{2}$, cada uma, com área total de amostragem de 3 hectares. 
Pires-O’Brien \& Michael-O'Brien (1995) assinalam a dificuldade na decisão sobre o tamanho das áreas de amostragem em estudos de florestas tropicais e acentuam que o conceito de área mínima revisado por Goodall (1954) refere-se ao menor tamanho da unidade de amostragem com a probabilidade de incluir uma proporção de, aproximadamente, $90 \%$ da flora total da localidade maior.

$\mathrm{Na}$ avaliação de uma comunidade vegetal, a definição de tamanho e forma de amostra ainda constitui problema (Jardim e Hosokawa, 1986/87).

Estudos realizados pela FAO (1974), de acordo com Oliveira Filho (1992), na República dos Camarões, revelam que quanto mais larga é uma amostra retangular, maior é a precisão, embora o tamanho seja mais importante sobre a precisão, do que a forma.

Silva e Lopes (1982) citados por Oliveira Filho (1992) acentuam que o tipo de distribuição espacial das espécies influencia tanto o esquema de amostragem quanto o tamanho e a forma das unidades de amostra. O autor refere-se também à colocação de Barros e Machado (1984) que ressaltam a importância do estudo da distribuição espacial das espécies da floresta amazônica como o ponto de partida para se entender as florestas tropicais e para o estudo detalhado dos seus componentes. Desta forma, quando a distribuição é agrupada, a amostragem sistemática resulta melhores estimativas assim como parcelas longas e estreitas (1000 × $10 \mathrm{~m})$ mostraram ser mais eficientes para este tipo de distribuição.

Abordando a eficiência estatística de parcelas com diferentes formas e tamanhos, na amostragem de florestas, Bormann (1953) citado 
por Martins (1979) ressalta que tanto o tamanho como a forma das parcelas influem nos valores de freqüência.

No método de parcelas, segundo Martins (1979), o tamanho das parcelas exerce influência nos resultados das estimativas de freqüência e de densidade por área.

Veloso e Klein (1957) citados por Negreiros (1982) adotaram o processo de amostragem preconizado por Mueller -Dombois e Ellenberg (1974) de distribuição de parcelas sob a forma de malha ,ao invés de parcelas isoladas e aleatórias, para determinar a área mínima de comunidades da mata pluvial do sul do Brasil. Neste estudo ,os autores adotaram a malha de parcelas com $16,0 \mathrm{~m}^{2}$,chegando a valores variando de $900,0 \mathrm{~m}^{2}$ à $1400,0 \mathrm{~m}^{2}$, recomendando o emprego de $1600 \mathrm{~m}^{2}$.

Para a obtenção de resultados numéricos precisos as parcelas a serem investigadas devem ter tamanho definido, de acordo com Braun-Blanquet (1932). Acentua , o autor, que a exatidão do resultado obtido aumenta com o número de áreas amostradas e com a igualdade da distribuição das espécies por toda a comunidade. E que o tamanho da parcela pode variar, mas depende do tipo de vegetação a ser estudada, assinalando que as formas quadradas ou no mínimo retangulares são as melhores.

Conforme Silva \& Lopes (1984) o tamanho da parcela mais eficiente, depende dos objetivos, da precisão requerida, da variabilidade da floresta e dos custos presentes e futuros.

Silva (1980), citado por Silva \& Lopes (1984) quanto à eficiência de diversos tamanhos e formas de unidades de amostra em amostragem aleatória, na Floresta Nacional do Tapajós (PA), definiu o 
tamanho de $2500 \mathrm{~m}^{2}(50 \mathrm{~m} \times 50 \mathrm{~m})$ como mais eficiente, para as condições do estudo, comparado aos vários tamanhos testados.

No estudo sobre a estrutura florística da floresta tropical efetuado em Mérida, Venezuela, Lamprecht (1964) usou três parcelas de um hectare, cada uma, chegando à conclusão que, para as condições locais, amostra de um hectare é suficiente. Recomenda o emprego de métodos estatísticos desde a compilação e avaliação dos dados de campo até a interpretação e comparação dos resultados.

Enfocando a floresta pluvial tropical da costa atlântica sulbrasileira, Veloso e Klein (1968) amostraram diferentes altitudes da encosta, evidenciando que um grande número de espécies tem preferência por condições físicas determinadas de solo. As amostras totalizaram sete quadrados de $1600 \mathrm{~m}^{2}$ cada um, subdivididos em 16 parcelas de $100 \mathrm{~m}^{2}$.

Stein (1993) preconiza que vários tamanhos e formas de parcelas de área fixa tem sido usados em vários modelos de amostragem aleatória e sistemática. Os mesmos tamanhos, formas e distribuição de tais parcelas podem servir a três objetivos distintos de avaliação:

1) determinação da presença ou ausência de árvores, espécies ou outros objetos de interesse;

2) obtenção de uma estimativa quantitativa de árvores, vegetação ou outros objetivos por unidade de área;

3) medições de mudanças em número, tamanho ou composição de árvores, vegetação ou outros objetivos.

Deve-se pesquisar um tamanho ótimo de parcela nas diferentes regiöes e para cada tipo florestal, conforme Couto (1984) e, quanto à forma deve-se ter o mesmo procedimento, pois quando se 
acentua 0 declive, as formas se modificam de quadradas para retangulares.

Husch et al. (1971) citados por Higuchi et al. (1982) afirmam que a área basal, em $\mathrm{m}^{2}$ de cada parcela, constitui uma característica muito útil de um povoamento florestal. É uma medida de densidade do povoamento, além de se relacionar diretamente com o volume. Ressaltam que densidade é uma medida quantitativa de um maciço florestal em termos de área basal refletindo a ocupação das árvores dentro de uma determinada área.

Dentre as variáveis que podem caracterizar um tipo florestal Couto (1984) considera a área basal por classe de diâmetro, o número de árvores por hectare, a altura das árvores dominantes e co-dominantes, entre outras.

Com o objetivo de eleger o processo de amostragem mais simples, Dias et al. (1986) desenvolveram estudo no Núcleo Sete Barras, Parque Estadual de Carlos Botelho, empregando parcelas de tamanho fixo e métodos de distância, utilizando o IVI como parâmetro de comparação. Os autores acentuaram a dificuldade em se empregar parcelas de tamanho fixo, na amostragem de comunidades florestais na serra do Mar devido à topografia acidentada.

Lamprecht (1990) acentua serem poucas as informações disponíveis quanto ao tamanho requerido para garantir a representatividade de uma amostragem, à vista dos processos dinâmicos, em particular as fases de desenvolvimento num determinado tipo florestal.

Pearce (1953), citado por Pimentel-Gomes (1984), assinala que, no estudo de árvores, devem-se usar parcelas pequenas, para 
economizar área, enquanto para economizar trabalho especializado devem ser preferidas parcelas grandes.

Outros métodos menos tradicionais que a curva espécie-área tem sido empregado para se determinar o tamanho de parcelas em florestas tropicais. Pimentel-Gomes (1984) sugeré o uso do coeficiente de correlação intraclasse $(p)$ relativo às árvores úteis dentro de cada parcela, definindo como tamanho ótimo o número $(k)$ de árvores úteis que minimize a variância da média de um tratamento para um número total de árvores $(\mathrm{N})$, considerado fixo.

O método do coeficiente de correlação intraclasse foi usado para definir o tamanho de parcelas na Reserva Florestal de Linhares, por Jesus et al. (não publicado). Recomendaram unidades amostrais de $20 x$ $80 \mathrm{~m}$ para se amostrar a densidade de árvores da floresta.

Higuchi et al. (1982) testaram vários tamanhos de parcelas para determinar o melhor dentre eles, para floresta tropical úmida de terrá-firme região Amazônica, utilizaram a Eficiência Relativa (ER), proposta por Husch et al. (1971), considerando custo de medição e precisão desejada. Para reforçar a comparação entre diferentes tamanhos de parcelas amostrais calcularam, também, o Limite de Erro (LE), o coeficiente de variação (CV), o número de parcelas ( $n$ ) para o inventário definitivo e a área total de amostragem (An). O parâmetro usado foi área basal em $\mathrm{m}^{2}$ de cada parcela. A parcela que apresentou melhores resultados foi a de $37,5 \times 150 \mathrm{~m}$.

Scolforo et al. (1993) empregaram os métodos: curva coeficiente de variação-área e eficiência relativa, considerando tempo dispendido ao invés de custo, para a definição de tamanhos de parcelas para inventários em floresta semidecidua montana, sul de Minas Gerais. 
Concluíram que para plantas com mais de $5 \mathrm{~cm}$ de DAP o comprimento ótimo da parcela, para qualquer largura está em torno de 100 a $110 \mathrm{~m}$. A partir da eficiência relativa o melhor tamanho de parcela é o de $20 \mathrm{x}$ $115 \mathrm{~m}$, pois apresenta menor erro padrão da média em porcentagem. 0 parâmetro utilizado foi volume da parcela, obtido da soma dos volumes de cada árvore. 


\section{MATERIAIS E MÉTODOS}

\subsection{Caracteristicas do Local}

A área do estudo compreende um trecho do Parque Estadual de Carlos Botelho, situado na região sul do estado de São Paulo. Constitui-se em uma das Unidades de Conservação administrada pelo Instituto Florestal, órgão da Secretaria do Meio Ambiente.

Este Parque totaliza $37.797,43$ hectares abrangendo os municipios de Sete Barras, São Miguel Arcanjo e Capão Bonito. Encontrase entre as coordenadas geográficas $24^{\circ} 00^{\prime}$ a $24^{\circ} 15^{\prime}$ de Latitude Sul e $47^{\circ} 45^{\prime}$ a $48^{\circ} 10^{\prime}$ de Longitude Oeste (FIGURA 1).

A cobertura vegetal da área é definida como floresta latifoliada tropical úmida de encosta (Heinsdijk e Campos, 1967; Romariz, 1964), floresta pluviosa tropical (Negreiros, 1982) e floresta ombrófila densa ( IBGE, 1988), sendo esta última a classificação mais atual para a área.

O relevo varia com altitudes de 30 a $1003 \mathrm{~m}$, conforme Domingues e Silva (1988) e compreende duas unidades geomorfológicas: o planalto de Guapiara e a serra de Paranapiacaba.

Os solos ocorrentes no Parque abrangem os tipos: Latossolo Vermelho-Amarelo (LV), Podzólico Vermelho-Amarelo "intergrade" para Latossolo Vermelho-Amarelo (PVL), Latossolo Vermelho-Amarelo "intergrade" para Podzólico Vermelho-Amarelo (LVP), solos de Campos do Jordão ( $L$ J) e Litossolo-fase substrato granito-gnaisse (Li-gr), conforme Pfeifer et al. (1986). 


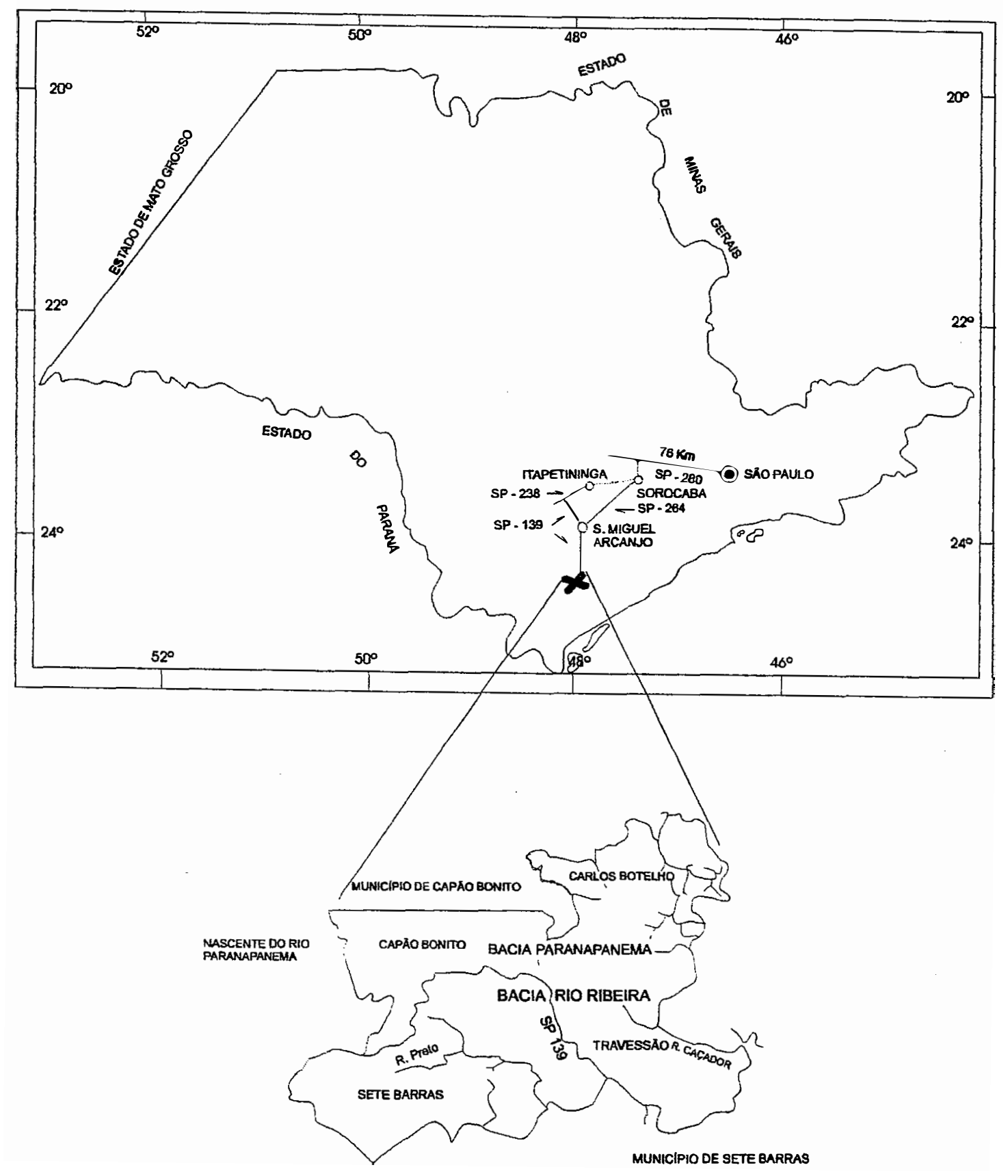

FIGURA 1 - Localização do Parque Estadual de Carlos Botelho - SP. 
Com base na classificação de Koeppen, Setzer (1946) atribui para a região os tipos climáticos Cfa e Cfb, ambos sem estiagem. O clima Cfa definido como mesotérmico úmido, com temperaturas superiores à $22^{\circ} \mathrm{C}$ no verão e acima de $30 \mathrm{~mm}$ de chuva no mês mais seco, sendo o índice pluviométrico entre 1100 a $1700 \mathrm{~mm}$. O tipo $\mathrm{Cfb}$, mesotérmico úmido, com a temperatura média do mês mais quente não atingindo a $22^{\circ} \mathrm{C}$ e precipitação de 1100 a $2000 \mathrm{~mm}$, constituindo clima de região serrana (Ventura, 1964).

\subsection{Procedimento no Campo}

\subsubsection{Seleção da área do estudo}

A área de estudo selecionada constitui-se em um trecho de mata secundária, em floresta atlântica, preservada desde 1941. Situa-se na região norte do Parque, no planalto de Guapiara, que pertence à bacia do rio Taquaral, com uma amplitude de variação altitudinal de 700 a 760 m.

\subsubsection{Amostragem}

Para a amostragem em campo, foi utilizado o método de parcelas. Em cinco locais diferentes foram implantadas 5 parcelas de 10 $\mathrm{m} \times \mathbf{2 0 0} \mathrm{m}$ cada uma, isto é, com área de $2000 \mathrm{~m}^{2}$. Foi estabelecida a distância mínima de $100 \mathrm{~m}$ entre as parcelas. A área da amostragem abrangeu um total de $10.000 \mathrm{~m}^{2}$, ou seja, um hectare.

Cada parcela foi subdividida em 10 subparcelas de $10 \mathrm{~m} \times 20$ m, $200 \mathrm{~m}^{2}$ cada uma. 
Em cada subparcela foram medidas as árvores com DAP a partir de $5 \mathrm{~cm}$ e registrado o nome comum identificado pelo mateiro e características dos indivíduos.

\subsection{Procedimento no laboratório}

A classificação botânica das espécies foi definida utilizandose das informações obtidas no campo, isto é, características e nome vulgar dos indivíduos amostrados e da literatura existente pertinente.

Os parâmetros fitossociológicos de densidade, de freqüência e de dominância foram baseados em Mueller-Dombois \& Ellenberg (1974). A combinação desses três parâmetros, expressa pela soma de seus valores relativos constituem o IVI (Índice de Valor de Importância). Este índice indica a importância de cada espécie na comunidade florestal, possibilitando uma visão mais ampla da estrutura das espécies na biocenose florestal. O IVI foi determinado conforme Curtis \& McIntosch (1951).

Lamprecht (1964) e Forster (1973), citado em Rosot et al. (1982), consideram que a abundância, a dominância e a freqüência caracterizam parcialmente a composição florística de uma floresta, tais parâmetros isolados não informam sobre a estrutura da vegetação.

O Indice de Valor de Cobertura (IVC) foi determinado conforme proposto por Forster, citado em Rosot et al. (1982), combinando os valores relativos de dominância e densidade.

Para determinar a diversidade da comunidade estudada empregou-se o índice de Shannon, de acordo com Pielou (1975). Para indicar a eqüabilidade da comunidade em estudo utilizou-se a proposição de Pielou (1975). Empregou-se o quociente de mistura (QM) que 
conforme Lamprecht (1964) fornece o número médio de plantas por espécie, na área estudada, facilitando a análise da composição florística.

\subsubsection{Cálculo dos parâmetros fitossociológicos}

Para a análise da estrutura da floresta em estudo consideram-se os parâmetros: densidade (De), freqüência (Fr) e dominância (Do) em seus valores absolutos e relativos. Os valores absolutos obtidos através das fómulas:

Densidade absoluta - De $=\frac{n^{\circ} . \text { de indiv. da espécie }}{\text { área amostrada }}$

Freq. absoluta $-\mathrm{Fr}=\frac{\text { sub-parcelas com a espécie }}{n^{\circ} \text { de sub-parcelas }} \times 100$

área basal da espécie

Dom. absoluta - Do $=$

$$
\text { área amostrada }
$$

Os valores relativos obtidos a partir dos valores absolutos:

Dens. relativa - DeR $=\frac{\text { De da espécie }}{\Sigma \text { De de todas as espécies }} \times 100$

Freq. relativa $-\mathrm{FrR}=\frac{\mathrm{Fr} \text { da espécie }}{\sum \text { Fr de todas as espécies }} \times 100$

Dom. relativa - DoR $=\frac{\text { Do da espécie }}{\Sigma \text { Do de todas as espécies }} \times 100$


Os valores relativos de densidade, freqüência e dominância permitem o cálculo do índice de Valor de Importância (IVI) através de:

$$
\text { IVI }=\text { DeR + FrR + DoR }
$$

Para obtenção da área basal individual (g) emprega -se:

$$
g=\pi / 4 \times \mathrm{DAP}^{2} \simeq 0,7854 \times \mathrm{DAP}^{2}
$$

O índice de diversidade foi calculado por:

onde: $\mathrm{pi}=\mathrm{ni} / \mathrm{N}, \mathrm{e}$

$$
H^{\prime}=-\sum_{i=1}^{S} p i(\ln p i)
$$

$\mathrm{S}=$ número de espécies amostradas;

ni = número de indivíduos da espécie $\mathrm{i}$;

$\mathrm{N}=$ número de individuos da amostra;

Ln = logaritmo neperiano

A equabilidade foi determinada de acordo com a fórmula:

$$
J^{\prime}=H^{\prime} / H \max
$$

sendo:

$H^{\prime}=$ indice de diversidade

$H \max =\mathrm{Ln} S$, onde $\mathrm{S}=$ número de espécies amostradas.

O quociente de mistura (QM) foi calculado conforme: 
Para análise da distribuição diamétrica das principais espécies foi empregada a fórmula apresentada em Spiegel (1976), a qual determina a amplitude da classe de diâmetro a partir do número de árvores e da amplitude diamétrica da espécie:

$$
I C=A /[1+3,3 \log (n)]
$$

onde:

IC = intervalo de classe de diâmetro da espécie;

$A=$ amplitude diamétrica (diferença entre o maior e o menor diâmetro da espécie);

$\log =$ logaritmo na base 10 ;

$\mathrm{n}=$ número de árvores amostradas da espécie.

3.3.2 Método do coeficiente de correlação intraclasse

Para a determinação do tamanho e número de parcelas empregou-se o método do Coeficiente de Correlação Intraciasse. Pimentel-Gomes \& Couto (1985) e Pimentel-Gomes \& Chaves (1988) propuseram uma metodologia para definir o tamanho e o número de parcelas adequados para levantamentos florestais.

Esse método preconiza que, a partir de um número $\mathbf{r}$ de parcelas, subdivididas em $\mathbf{k}$ subparcelas por parcela, pode-se determinar - número ótimo de subparcelas $k^{\prime}$ para inventário. $O$ procedimento, descrito pelos autores, pode ser simplificado da seguinte forma:

a) O número ótimo de subparcelas $\mathbf{k}^{3}$ é obtido em função da estimativa de $\rho$, isto é, coeficiente de correlação intraclasse e do valor f: 


$$
k^{\prime}=\sqrt{\frac{f(1-\rho)}{p}}
$$

onde:

- f é a relação c1/c2, em que c1 é o custo para medição de cada subparcela e c2 é o custo de acesso a cada parcela, sendo considerado neste trabalho como sendo igual a 1 ;

- $\rho$ é obtido a partir das esperanças dos quadrados médios, conforme 0 quadro de análise de variância:

\begin{tabular}{llll}
\hline Causa da variação & $G L$ & $Q M$ & $E(Q . M)$. \\
\hline Entre Parcelas & $n 1=r-1$ & $V 1$ & $\sigma^{2}[1+(k-1) \rho]$ \\
Entre Subparcelas & $n 2=r(k-1)$ & $V 2$ & $\sigma^{2}(1-\rho)$ \\
\hline
\end{tabular}

Baseado na esperança do quadrado médio - $E(Q M)$ - temos que:

$V 1=\sigma^{2}[1+(k-1) \rho]$ e $V 2=\sigma^{2}(1-\rho)$, obtendo-se:

$$
\rho=\frac{V 1-V 2}{V 1+V 2(k-1)}
$$

b) Obtido o número ótimo de subparcelas ( $\left.k^{\prime}\right)$, calcula-se 0 número de parcelas do levantamento $\left(r^{\prime}\right)$, visando minimizar o erro padrão da média e mantendo-se o custo inicial do levantamento. Com esse procedimento está-se otimizando o desenho ou delineamento amostral inicial:

$$
r^{\prime}=r \frac{f+k}{f+k^{\prime}}
$$


c) A estimativa da variância da média $V(m)$ que era:

$$
V(m)=\frac{\sigma^{2}[1+(k-1) \rho]}{k r}
$$

passa a ser:

$$
V(m)^{\prime}=\frac{\sigma^{2}\left[1+\left(k^{\prime}-1\right) \rho\right]}{k^{\prime} r^{\prime}}
$$

onde: $\sigma^{2}=V 2 /(1-\rho)$

d) A redução $(\Delta)$ no erro padrão da média é dada pela relação:

$$
\Delta=1-\sqrt{\frac{V(m)^{\prime}}{V(m)}}
$$




\section{RESULTADOS E DISCUSSÃO}

\subsection{Fitossociologia}

Nas 5 parcelas utilizadas para a amostragem da vegetação, perfazendo uma área de um hectare, foram detectados 1685 indivíduos arbóreos com diâmetro a altura do peito (DAP) a partir de $5 \mathrm{~cm}$. Foram amostradas 105 espécies, 65 gêneros e 34 famílias, considerando-se as não identificadas que foram incluidas como morfo-espécies (TABELA 1).

Dentre as familias classificadas, as que se destacaram pelo maior número de espécies foram: Leguminosae, Myrtaceae, Lauraceae, Rubiaceae e Euphorbiaceae.

TABELA 1 - Composição florística de espécies arbóreas num trecho de mata secundária do Parque Estadual de Carlos Botelho (SP).

\begin{tabular}{|l|l|l|}
\hline Familia & Nome científico & Nome comum \\
\hline Anacardiaceae & Tapinira guianensis Aubl. & pau-de-pomba \\
\hline & & \\
\hline Annonaceae & Rollinia sp1 & araticum \\
\hline & Rollinia sp2 & araticum-cagão \\
\hline & Xylopia brasiliensis Spreng. & pindaúva-vermelha \\
\hline & Guatteria sp. & pindaúva \\
\hline Apocynaceae & Aspidosperma olivaceum M. Arg. & \\
\hline & & guatambu \\
\hline Araliaceae & Didymopanax sp. & \\
\hline & & mandioqueira \\
\hline Bignoniaceae & Jacaranda puberula Cham. & \\
\hline & Jacaranda sp. & caroba \\
\hline & Tabebuia impetiginosa (Mart.) Standl. & jacarandá \\
\hline & & \\
\hline Boraginaceae & Cordia sp. & juruté \\
\hline & & \\
\hline Burseraceae & Protium heptaphyllum (Aubl.) March. & amescla \\
\hline & Protium sp. & amescla-branca \\
\hline & & \\
\hline Canellaceae & Capsicodendron dinisii (Schw.) Occhioni & pimenteira \\
\hline & &
\end{tabular}


Tabela 1 - Continuaçăo.

\begin{tabular}{|c|c|c|}
\hline Familia & Nome cientifico & Nome comum \\
\hline \multirow[t]{2}{*}{ Chrysobalanaceae } & Licania sp. & milho-cozido \\
\hline & Hirtella hebeclada Moric. & simbiuva \\
\hline Combretaceae & Buchenavia kleinii Excell & amarelinho \\
\hline \multirow[t]{2}{*}{ Compositae } & Piptocarpha sp. & cambará-pólvora \\
\hline & Piptocarpha axillaris Baker & cambará-branco \\
\hline Cunoniaceae & Weinmania sp. & cupiúva \\
\hline \multirow{4}{*}{ Euphorbiaceae } & Alchomea triplinervia M. Ara. & tapiá \\
\hline & Hyeronima alchomeoides Fr. Allen & urucurana \\
\hline & $\begin{array}{l}\text { Pachystroma longifolium (Nees) I. M. } \\
\text { John }\end{array}$ & caxim \\
\hline & Pera glabrata (Schott) Baill. & tabucuva \\
\hline \multirow[t]{3}{*}{ Flacourtiaceae } & Casearia sp. & guaçatonga \\
\hline & Casearia sylvestris Sw. & erva-de-macuco \\
\hline & Xylosma salzmani (Clos) Eichl. & espinho-de-judeu \\
\hline \multirow[t]{5}{*}{ Lauraceae } & Lauraceae 1 & canela \\
\hline & Lauraceae 2 & nhutinga \\
\hline & Ocotea sp. & canelinha \\
\hline & Nectandra sp. & canela-amarela \\
\hline & Ocotea odorifera (Vell.) Rohwer & sassafrás \\
\hline \multirow[t]{4}{*}{ Legum. Caesalpi. } & Hymenaea sp. & jataieiro-bravo \\
\hline & Sclerolobium denudatum Vog. & passuaré \\
\hline & Copaifera langsdorffii Desf. & copaíba \\
\hline & $\begin{array}{l}\text { Senna multijuga (L. C. Rich.) Inw. \& } \\
\text { Bam. }\end{array}$ & caquera \\
\hline \multirow[t]{2}{*}{ Legum. Mimosoi. } & Inga sellowiama Benth. & inga-ferro \\
\hline & Inga sp. & inga \\
\hline \multirow[t]{6}{*}{ Legum. Papilion. } & Dalbergia sp1. & rabo-de-bugio \\
\hline & Pterocarpus violaceus Vog. & pau-sangue \\
\hline & Dalbergia sp2 & caviúna \\
\hline & Machaerium sp. & bico-de-pato \\
\hline & Myroxylon peruiferum L. f. & cabriuva \\
\hline & Ormosia sp. & olho-de-cabra \\
\hline
\end{tabular}


Tabela 1 - Continuação.

\begin{tabular}{|c|c|c|}
\hline Familia & Nome científico & Nome comum \\
\hline Magnoliaceae & Talauma ovata St. Hil. & baguaçu \\
\hline \multirow[t]{3}{*}{ Melastomataceae } & Miconia cabucu Hoehne & pixiricão \\
\hline & Miconia theaezans Cogn. & pixirica \\
\hline & Trbouchina pulchra Cogn. & jacatirão \\
\hline \multirow{2}{*}{ Meliaceae } & Cabralea canjerana (Vell.) Mart. & canjerana \\
\hline & Cedrela fissilis Vell. & cedro \\
\hline \multirow[t]{2}{*}{ Moraceae } & Coussapoa microcarpa (Schott) Rizz. & mata-pau \\
\hline & Ficus sp. & figueira \\
\hline \multirow[t]{2}{*}{ Myrsinaceae } & Rapanea fermginea (Ruiz et Pav.) Mez. & capororoca-vermelha \\
\hline & Rapanea umbellata (Mart.) Mez. & capororoca \\
\hline \multirow[t]{6}{*}{ Myrtaceae } & $\begin{array}{l}\text { Campomanesia guaviroba (A.DC.) } \\
\text { Kiaersk. }\end{array}$ & guabiroba \\
\hline & Eugenia brasiliensis Lam. & grumixava \\
\hline & Eugenia uniflora L. & pitanga \\
\hline & Psidium cattleianum Sabine & araçá-da-mata \\
\hline & Psidium sp1. & araçá \\
\hline & Psidium sp2. & araçá-do-campo \\
\hline Nyctaginaceae & Guapira opposita (Vell.) Reitz & capa-rosa \\
\hline \multirow[t]{3}{*}{ Palmae } & Attalea dubia (Mart.) Burr. & nhanga \\
\hline & Euterpe edulis Mart. & palmito \\
\hline & Syagrus romanzoffiana (Cham.) Glass. & jerivá \\
\hline Proteaceae & Roupala brasiliensis Klotzsch & carne-de-vaca \\
\hline Rhamnaceae & Colubrina glandulosa Perkins & sabiaeiro \\
\hline Rosaceae & Prunus sellowi Koehne & miguel-pintado \\
\hline \multirow[t]{4}{*}{ Rubiaceae } & Bathysa meridionalis Smith \& Downs & fumão \\
\hline & Psychotria sp1. & erva-de-anta-grande \\
\hline & Psychotria sp2. & erva-de-anta \\
\hline & Psychotria sp3. & erva-de anta-miúda \\
\hline Rutaceae & $\begin{array}{l}\text { Balfourodendron riedelianum (Engl.) } \\
\text { Engl. }\end{array}$ & marfim \\
\hline
\end{tabular}


Tabela 1 - Continuaçăo.

\begin{tabular}{|c|c|c|}
\hline Familia & Nome cientifico & Nome comum \\
\hline & Esenbeckia grandiflora Mart. & canela-de-cutia \\
\hline & Zanthoxylum moifolium Lam. & mamica-de-porca \\
\hline \multirow[t]{2}{*}{ Sapindaceae } & Allophylus sp. & vacupari \\
\hline & Cupania vemalis Camb. & cuvantã \\
\hline \multirow[t]{2}{*}{ Sapotaceae } & Pouteria Sp. & guapevinha \\
\hline & Pouteria torta (Mart.) Radlk. & guapeva \\
\hline Solanaceae & Solanum inaequale Vell. & canema \\
\hline Tiliaceae & Luehea sp. & vatinguinha \\
\hline \multirow[t]{2}{*}{ Verbenaceae } & Vitex polvaama Cham & tarumã \\
\hline & & \\
\hline \multirow{24}{*}{ Não identificada } & não identificada & abacateiro \\
\hline & não identificada & aleixo \\
\hline & não identificada & caingá-mirim \\
\hline & não identificada & canafístula \\
\hline & não identificada & canela-de-veado \\
\hline & não identificada & casca-grossa \\
\hline & não identificada & cipó-braço-de-rei \\
\hline & não identificada & cipó-marmelo \\
\hline & não identificada & erva-de-cavalo \\
\hline & não identificada & erva-de-pomba \\
\hline & não identificada & goiabeira-branca \\
\hline & não identificada & goiabeira-vermelha \\
\hline & não identificada & guacarana \\
\hline & não identificada & guarapari \\
\hline & não identificada & guarapari-vermelho \\
\hline & não identificada & inhuva-roque \\
\hline & não identificada & jacuntigueira \\
\hline & não identificada & lima-de-mico \\
\hline & não identificada & lima-de-mico-miúda \\
\hline & não identificada & lima-de-mono \\
\hline & não identificada & maçuarã \\
\hline & não identificada & marmelinho \\
\hline & não identifícada & quina \\
\hline & não identificada & quina-amarela \\
\hline
\end{tabular}




\subsubsection{As Espécies e seus Parâmetros Fitossociológicos}

$\mathrm{Na}$ TABELA 2 constam as espécies amostradas e os parâmetros fitossociológicos de dominância, densidade e freqüência em valores absolutos e relativos, Índice de Valor de Cobertura (IVC) e Índice de Valor de Importância (IVI).

TABELA 2 - Parâmetros fitossociológicos das espécies amostradas em ordem decrescente de IVI (Índice de Valor de Importância), onde Do=dominância absoluta; De=densidade absoluta; Fr=frequência absoluta; IVC=indice de Valor de Cobertura; DoR, DeR e FrR são os parâmetros relativos.

\begin{tabular}{|c|c|c|c|c|c|c|c|c|c|}
\hline OBS & ESPÉCIE & Do & De & $\mathbf{F r}$ & DoR & DeR & FrR & IVI & IVC \\
\hline 1 & Ocotea sp. & 1.96 & 131 & 88 & 5.60 & 7.77 & 5.20 & 18.58 & 13.38 \\
\hline 2 & Tibouchina pulchra & 2.81 & 77 & 44 & 8.05 & 4.57 & 2.60 & 15.22 & 12.62 \\
\hline 3 & morta & 1.67 & 86 & 78 & 4.77 & 5.10 & 4.61 & 14.48 & 9.87 \\
\hline 4 & Psychotria sp2 & 1.58 & 65 & 60 & 4.52 & 3.86 & 3.55 & 11.92 & 8.38 \\
\hline 5 & Solanum inaequale & 1.38 & 69 & 42 & 3.95 & 4.10 & 2.48 & 10.52 & 8.04 \\
\hline 6 & Eugenia brasiliensis & 2.68 & 22 & 20 & 7.66 & 1.31 & 1.18 & 10.14 & 8.96 \\
\hline 7 & Roupala brasiliensis & 0.99 & 57 & 56 & 2.82 & 3.38 & 3.31 & 9.52 & .21 \\
\hline 8 & Guatteria sp. & 0.40 & 56 & 60 & 1.15 & 3.32 & 3.55 & 8.02 & 4.48 \\
\hline 9 & Rapanea ferruginea & 0.66 & 43 & 38 & 1.87 & 2.55 & 2.25 & 6.67 & 4.43 \\
\hline 10 & Euterpe edulis & 0.21 & 43 & 52 & 0.60 & 2.55 & 3.07 & 6.22 & 3.15 \\
\hline 11 & Hyeronima alchomeoides & 0.37 & 46 & 36 & 1.06 & 2.73 & 2.13 & 5.92 & 3.79 \\
\hline 12 & Weinmania sp. & 0.72 & 25 & 34 & 2.07 & 1.48 & 2.01 & 5.57 & 3.56 \\
\hline 13 & Cabralea canjerana & 0.42 & 32 & 40 & 1.21 & 1.90 & 2.36 & 5.48 & 3.11 \\
\hline 14 & Nectandra sp. & 1.26 & 9 & 16 & 3.59 & 0.53 & 0.95 & 5.07 & 4.13 \\
\hline 15 & Pouteria torta & 0.50 & 23 & 34 & 1.43 & 1.37 & 2.01 & 4.80 & 2.79 \\
\hline 16 & marmelinho & 0.34 & 26 & 38 & 0.96 & 1.54 & 2.25 & 4.75 & 2.51 \\
\hline 17 & Cordia sp. & 0.31 & 23 & 36 & 0.88 & 1.37 & 2.13 & 4.37 & 2.25 \\
\hline 18 & Sclerolobium denudatum & 0.78 & 14 & 22 & 2.23 & 0.83 & 1.30 & 4.36 & 3.06 \\
\hline 19 & Jacaranda puberula & 0.22 & 31 & 26 & 0.62 & 1.84 & 1.54 & 4.00 & 2.46 \\
\hline 20 & Hymenaea sp. & 0.72 & 14 & 18 & 2.06 & 0.83 & 1.06 & 3.95 & 2.89 \\
\hline 21 & Copaifera langsdorffi & 0.68 & 13 & 20 & 1.96 & 0.77 & 1.18 & 3.91 & 2.73 \\
\hline 22 & Lauraceae 2 & 1.01 & 7 & 8 & 2.89 & 0.42 & 0.47 & 3.77 & 3.30 \\
\hline 23 & Cupania vermalis & 0.23 & 20 & 32 & 0.65 & 1.19 & 1.89 & 3.72 & 1.83 \\
\hline 24 & Miconia theaezans & 0.10 & 26 & 32 & 0.28 & 1.54 & 1.89 & 3.71 & 1.82 \\
\hline 25 & Didymopanax sp. & 0.24 & 22 & 28 & 0.70 & 1.31 & 1.65 & 3.66 & 2.00 \\
\hline 26 & Pterocarpus violaceus & 0.64 & 13 & 18 & 1.82 & 0.77 & 1.06 & 3.66 & 2.59 \\
\hline 27 & maçuarã & 0.60 & 12 & 18 & 1.72 & 0.71 & 1.06 & 3.50 & 2.43 \\
\hline 28 & Colubrina grandulosa & 0.36 & 15 & 26 & 1.02 & 0.89 & 1.54 & 3.45 & 1.91 \\
\hline 29 & inhuva-roque & 0.33 & 15 & 26 & 0.94 & 0.89 & 1.54 & 3.37 & 1.83 \\
\hline 30 & Dalbergia sp1. & 0.38 & 13 & 18 & 1.10 & 0.77 & 1.06 & 2.93 & 1.87 \\
\hline 31 & Aspidosperma olivaceum & 0.54 & 6 & 10 & 1.54 & 0.36 & 0.59 & 2.49 & 1.89 \\
\hline
\end{tabular}


Tabela 2 - Continuação.

\begin{tabular}{|c|c|c|c|c|c|c|c|c|c|}
\hline BS & ESPECIE & Do & De & Fr & DoR & DeR & FrR & IVI & IVC \\
\hline 32 & Pouteria sp. & 0.22 & 11 & 20 & 0.62 & 0.65 & 1.18 & 2.45 & 1.27 \\
\hline 33 & lima-de-mico & 0.09 & 15 & 24 & 0.26 & 0.89 & 1.30 & 2.45 & 1.15 \\
\hline 34 & Casearia sp. & 0.18 & 14 & 16 & 0.52 & 0.83 & 0.95 & 2.29 & 1.35 \\
\hline 35 & Tapirira guianensis & 0.08 & 10 & 20 & 0.21 & 0.59 & 1.18 & 1.99 & 0.81 \\
\hline 36 & Bathysa meridionalis & 0.12 & 11 & 16 & 0.35 & 0.65 & 0.95 & 1.95 & 1.01 \\
\hline 37 & Prunus sellowi & 0.14 & 12 & 14 & 0.40 & 0.71 & 0.83 & 1.94 & 1.11 \\
\hline 38 & Myroxylon peruiferum & 0.21 & 8 & 14 & 0.59 & 0.47 & 0.83 & 1.89 & 1.06 \\
\hline 39 & Ocotea odorifera & 0.16 & 8 & 16 & 0.45 & 0.47 & 0.95 & 1.87 & 0.92 \\
\hline 40 & erva-de-cavalo & 0.20 & 8 & 14 & 0.56 & 0.47 & 0.83 & 1.86 & 1.03 \\
\hline 41 & Lauraceae 1 & 0.24 & 6 & 10 & 0.70 & 0.36 & 0.59 & 1.65 & 1.06 \\
\hline 42 & Piptocarpha axillaris & 0.14 & 10 & 10 & 0.39 & 0.59 & 0.59 & 1.57 & 0.98 \\
\hline 43. & Jacaranda sp. & 0.04 & 8 & 16 & 0.11 & 0.47 & 0.95 & 1.53 & 0.59 \\
\hline 44 & Piptocarpha sp. & 0.16 & 8 & 10 & 0.46 & 0.47 & 0.59 & 1.52 & 0.93 \\
\hline 45 & Ormosia sp. & 0.09 & 9 & 12 & 0.25 & 0.53 & 0.71 & 1.49 & 0.79 \\
\hline 46. & Zanthoxylum moifolium & 0.04 & 8 & 14 & 0.13 & 0.47 & 0.83 & 1.43 & 0.60 \\
\hline 47 & Alchomea triplinervia & 0.09 & 7 & 12 & 0.27 & 0.42 & 0.71 & 1.39 & 0.69 \\
\hline 48 & Buchenavia kleinii & 0.16 & 5 & 10 & 0.47 & 0.30 & 0.59 & 1.35 & 0.76 \\
\hline 49 & Licania sp. & 0.03 & 7 & 14 & 0.08 & 0.42 & 0.83 & 1.32 & 0.49 \\
\hline 50 & Rollinia sp1. & 0.13 & 6 & 10 & 0.36 & 0.36 & 0.59 & 1.31 & 0.72 \\
\hline 51 & guarapari & 0.11 & 8 & 8 & 0.31 & 0.47 & 0.47 & 1.26 & 0.79 \\
\hline 52. & Psidium sp1. & 0.06 & 6 & 12 & 0.18 & 0.36 & 0.71 & 1.24 & 0.53 \\
\hline 53 & Miconia cabucu & 0.02 & 7 & 12 & 0.06 & 0.42 & 0.71 & 1.19 & 0.48 \\
\hline 54 & abacateiro & 0.23 & 3 & 6 & 0.65 & 0.18 & 0.35 & 1.18 & 0.83 \\
\hline 55 & Hirtela hebeclada & 0.09 & 5 & 10 & 0.25 & 0.30 & 0.59 & 1.14 & 0.55 \\
\hline 56 & Campomanesia guaviroba & 0.09 & 5 & 10 & 0.25 & 0.30 & 0.59 & 1.13 & 0.54 \\
\hline 57 & Inga sp. & 0.14 & 4 & 8 & 0.40 & 0.24 & 0.47 & 1.11 & 0.63 \\
\hline 58 & Protium heptaphyllum & 0.03 & 6 & 10 & 0.10 & 0.36 & 0.59 & 1.05 & 0.45 \\
\hline 59 & Coussapoa microcarpa & 0.21 & 2 & 4 & 0.61 & 0.12 & 0.24 & 0.96 & 0.73 \\
\hline 60 & Esenbeckia grandiffora & 0.04 & 5 & 8 & 0.12 & 0.30 & 0.47 & 0.89 & 0.42 \\
\hline 61 & Psidium cattleianum & 0.06 & 4 & 8 & 0.17 & 0.24 & 0.47 & 0.88 & 0.41 \\
\hline 62 & Balfourodendron niedelianum & 0.24 & 1 & 2 & 0.69 & 0.06 & 0.12 & 0.87 & 0.75 \\
\hline 63 & Ficus sp. & 0.07 & 5 & 6 & 0.19 & 0.30 & 0.35 & 0.84 & 0.49 \\
\hline 64 & quina & 0.10 & 3 & 6 & 0.29 & 0.18 & 0.35 & 0.82 & 0.47 \\
\hline 65 & Talauma ovata & 0.16 & 2 & 4 & 0.47 & 0.12 & 0.24 & 0.82 & 0.59 \\
\hline 66 & Pachystroma longifolium & 0.03 & 4 & 8 & 0.08 & 0.24 & 0.47 & 0.79 & 0.32 \\
\hline 67 & lima-de-mico-miúda & 0.08 & 3 & 6 & 0.24 & 0.18 & 0.35 & 0.77 & 0.42 \\
\hline 68 & Dalbergia sp2. & 0.02 & 4 & 8 & 0.06 & 0.24 & 0.47 & 0.77 & 0.29 \\
\hline 69 & Cedrela fissilis & 0.01 & 4 & 8 & 0.04 & 0.24 & 0.47 & 0.75 & 0.28 \\
\hline 70 & Casearia sytuestris & 0.03 & 5 & 6 & 0.09 & 0.30 & 0.35 & 0.74 & 0.39 \\
\hline 71 & Inga sellowiana & 0.10 & 2 & 4 & 0.29 & 0.12 & 0.24 & 0.64 & 0.41 \\
\hline 72 & Psychotria sp1. & 0.01 & 4 & 6 & 0.04 & 0.24 & 0.35 & 0.63 & 0.27 \\
\hline 73 & 3 quina-amarela & 0.09 & 2 & 4 & 0.27 & 0.12 & 0.24 & 0.62 & 0.39 \\
\hline 74 & 4 Luehea sp. & 0.01 & 4 & 6 & 0.03 & 0.24 & 0.35 & 0.62 & 0.27 \\
\hline & 5apsicodendron dinisii & 0.08 & 2 & 4 & 0.22 & 0.12 & 0.24 & 0.57 & 0.34 \\
\hline 76 & Fsidium sp2. & 0.01 & 3 & 6 & 0.04 & 0.18 & 0.35 & 0.57 & 0.22 \\
\hline 77 & 7) Protium sp. & 0.02 & 3 & 4 & 0.05 & 0.18 & 0.24 & 0.47 & 0.23 \\
\hline 78 & Vitex polygama & 0.02 & 3 & 4 & 0.04 & 0.18 & 0.24 & 0.46 & 0.22 \\
\hline 79 & Xylosma salzmani & 0.01 & 5 & 2 & 0.04 & 0.30 & 0.12 & 0.45 & 0.34 \\
\hline
\end{tabular}


Tabela 2 - Continuação.

\begin{tabular}{|c|c|c|c|c|c|c|c|c|c|}
\hline OBS & ESPÉCIE & Do & De & $\mathbf{F r}$ & DoR & DeR & FrR & IVI & IVC \\
\hline 80 & jacutingueira & 0.02 & 2 & 4 & 0.04 & 0.12 & 0.24 & 0.40 & 0.16 \\
\hline 81 & canafistula & 0.07 & 1 & 2 & 0.21 & 0.06 & 0.12 & 0.39 & 0.27 \\
\hline 82 & Rollinia sp2. & 0.01 & 2 & 4 & 0.03 & 0.12 & 0.24 & 0.39 & 0.15 \\
\hline 83 & Attalea dubia & 0.07 & $\overline{1}$ & 2 & 0.20 & 0.06 & 0.12 & 0.37 & 0.26 \\
\hline 84 & caingá-mirim & 0.01 & 2 & 4 & 0.01 & 0.12 & 0.24 & 0.37 & 0.13 \\
\hline 85 & aleixo & 0.04 & 2 & 2 & 0.12 & 0.12 & 0.12 & 0.36 & 0.24 \\
\hline 86 & Syagrus romanzoffiana & 0.04 & $\frac{1}{1}$ & 2 & 0.13 & 0.06 & 0.12 & 0.31 & 0.19 \\
\hline 87 & guarapari-vermelho & 0.02 & 2 & 2 & 0.05 & 0.12 & 0.12 & 0.29 & 0.17 \\
\hline 88 & Senna multijuga & 0.01 & 2 & 2 & 0.03 & 0.12 & 0.12 & 0.27 & 0.15 \\
\hline 89 & Eugenia unifiora & 0.01 & 2 & 2 & 0.01 & 0.12 & 0.12 & 0.25 & 0.13 \\
\hline 90 & erva-de-pomba & 0.00 & 2 & 2 & 0.01 & 0.12 & 0.12 & 0.25 & 0.13 \\
\hline & guacarana & 0.02 & 1 & 2 & 0.07 & 0.06 & 0.12 & 0.25 & 0.13 \\
\hline 92 & casca-grossa & 0.02 & 1 & 2 & 0.06 & 0.06 & 0.12 & 0.23 & 0.12 \\
\hline 93 & Rapanea umbellata & 0.02 & 1 & 2 & 0.05 & 0.06 & 0.12 & 0.22 & 0.11 \\
\hline 94 & Psychotria sp3. & 0.01 & 1 & 2 & 0.04 & 0.06 & 0.12 & 0.22 & 0.10 \\
\hline & goiabeira-branca & 0.01 & 1 & 2 & 0.03 & 0.06 & 0.12 & 0.21 & 0.09 \\
\hline 96 & Machaerium sp. & 0.01 & 1 & 2 & 0.03 & 0.06 & 0.12 & 0.21 & 0.09 \\
\hline 97 & canela-de-veado & 0.01 & 1 & 2 & 0.02 & 0.06 & 0.12 & 0.20 & 0.08 \\
\hline & lima-de-mono & 0.01 & 1 & 2 & 0.02 & 0.06 & 0.12 & 0.20 & 0.08 \\
\hline 99 & Tabebuia impetiginosa & 0.01 & 1 & $\overline{2}$ & 0.01 & 0.06 & 0.12 & 0.19 & 0.07 \\
\hline 100 & Pera glabrata & 0.00 & 1 & 2 & 0.01 & 0.06 & 0.12 & 0.19 & 0.07 \\
\hline 101 & Guapira opposita & \begin{tabular}{|l|}
0.00 \\
\end{tabular} & 1 & 2 & 0.01 & 0.06 & 0.12 & 0.19 & 0.07 \\
\hline 102 & cipó-marmelo & 0.00 & 1 & 2 & 0.01 & 0.06 & 0.12 & 0.19 & 0.07 \\
\hline 103 & Xylopia brasiliensis & 0.00 & 1 & 2 & 0.01 & 0.06 & 0.12 & 0.19 & 0.07 \\
\hline 104 & Allophylus sp. & 0.00 & 1 & 2 & 0.01 & 0.06 & 0.12 & 0.19 & 0.07 \\
\hline 105 & goiabeira-vermelha & 0.00 & 1 & 2 & 0.01 & 0.06 & 0.12 & 0.19 & 0.07 \\
\hline 106 & cipó-braço-de-rei & 0.00 & 1 & 2 & 0.01 & 0.06 & 0.12 & 0.19 & 0.07 \\
\hline 107 & desconhecidas & 4.76 & 311 & 96 & 13.59 & 18.46 & 5.67 & 37.72 & 32.05 \\
\hline & TOTAL & 34.97 & 1685 & & 100.00 & 100.00 & 100.00 & 300.00 & 200.00 \\
\hline
\end{tabular}

A FIGURA 2 contem as 15 espécies mais importantes, relacionadas em ordem decrescente de IVI.

O IVI mais elevado da Ocotea sp. (canelinha), no valor de 18,58 coloca-a entre as ánores que melhor aproveitam as condiçōes do meio, sobressaindo-se entre as demais. Apresenta-se, também em primeiro lugar em termos de freqüência relativa $(F r R=5,2 \%)$ e densidade relativa (DeR=7,77\%), sendo que em relação à dominância relativa (DoR=5,6\%) a espécie ocupa o terceiro lugar.

Tais parâmetros evidenciam que a posição atingida, pela canelinha, deve-se principalmente à sua densidade. 
Klein (1980) citado por Negreiros et al. (1995) assinala que em matas secundárias mais desenvolvidas, da floresta pluvial sul brasileira, a família Lauraceae apresenta muitos exemplares jovens e somente alguns adultos. Enquanto Siqueira (1994) acentua que na mata atlântica, Lauraceae é a família que atinge maior distribuição, em comparação com as demais familias ocorrentes. Vale ressaltar que esta colocação é válida para o sul de São Paulo e os estados do Paraná e Santa Catarina.

Após a Ocotea sp., as cinco espécies com maiores IVI (FIGURA 2) são Tibouchina pulchra (jacatirão) 15,22, Psychotria sp2 (erva de anta) 11,92, Solanum inaequale (canema) 10,52, Eugenia brasiliensis (grumixava) 10,14 e Roupala brasiliensis (carne de vaca) 9,52 , que constituem $25,3 \%$ do IVI total da comunidade.

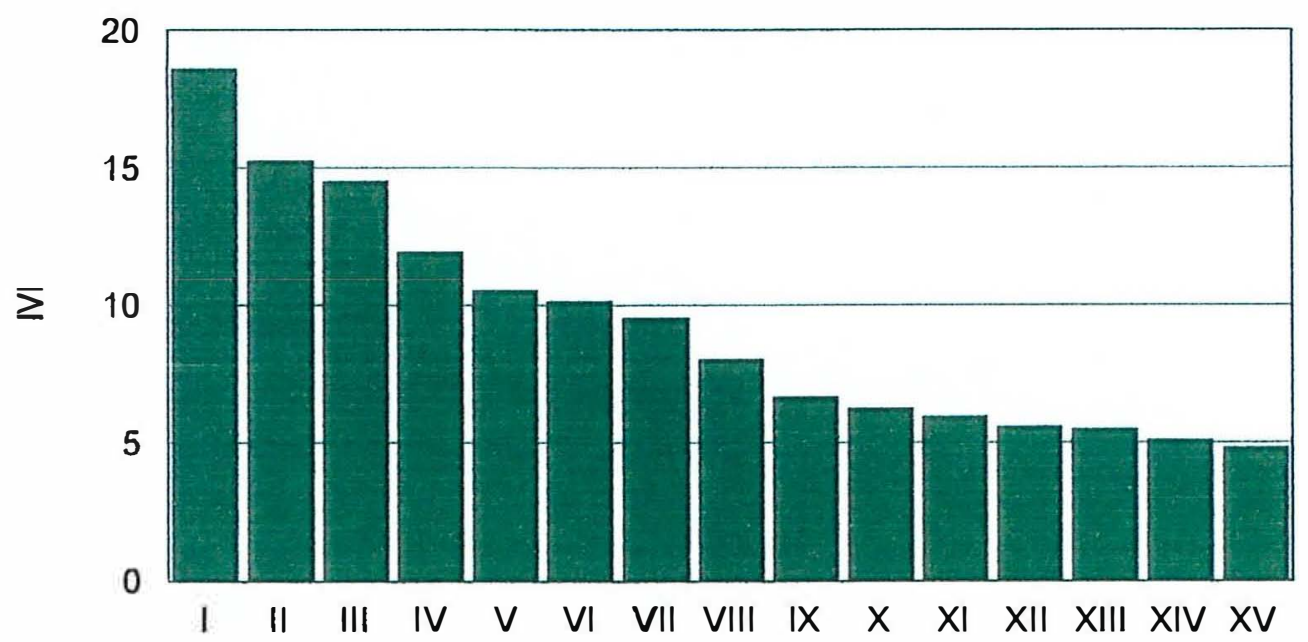

FIGURA 2 - IVI das 15 espécies mais importantes em uma mata secundária no Parque Estadual de Carlos Botelho, SP. I-Ocotea sp.; II-Tibouchina pulchra; III-Morta; IVPsychotria sp2; V-Solanum inaequale; VI-Eugenia brasiliensis; VII-Roupala brasiliensis; VIII-Guatteria sp.; IX-Rapanea ferruginea; X-Euterpe edulis; XIHyeronima alchomeoides; XII-Weinmania sp.; XIII-Cabralea canjerana; XIVNectandra sp.; XV-Pouteria torta. 
A FIGURA 3 contem as 15 espécies com os valores do índice de valor de cobertura (IVC) em ordem decrescente.

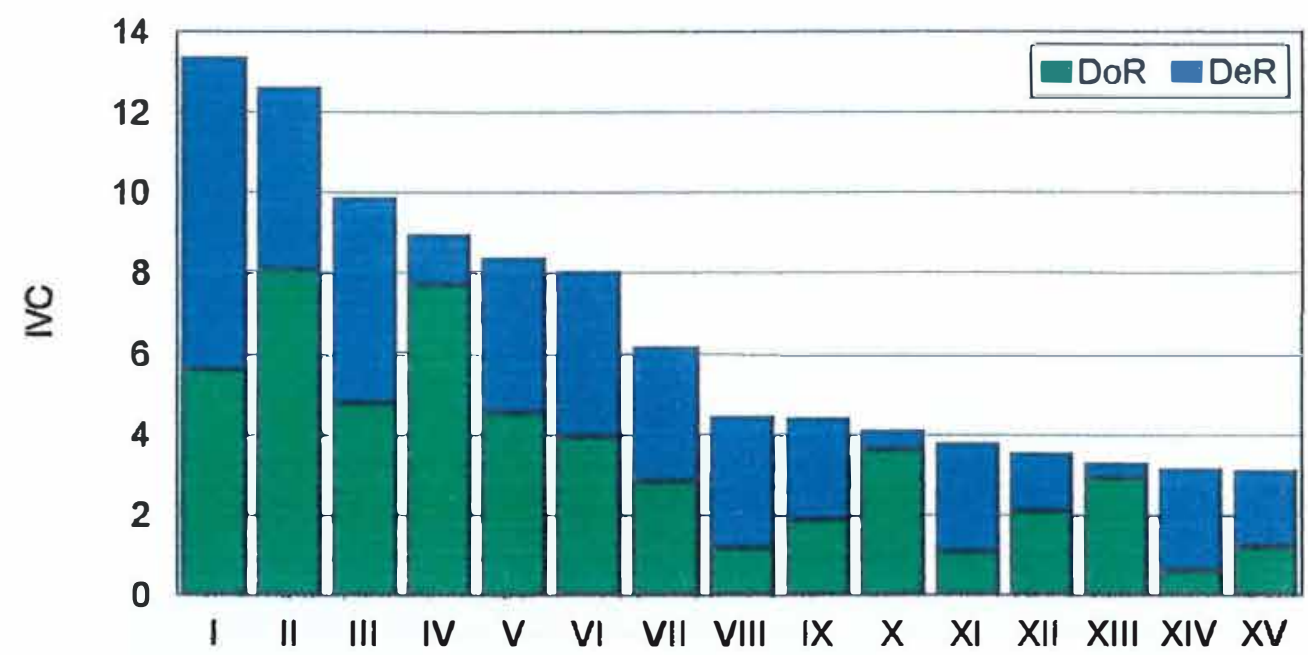

FIGURA 3 - IVC das 15 espécies com maiores valores e a participacão da dominância e densidade relativas em uma mata secundária no Parque Estadual de Carlos Botelho, SP. I-Ocotea Sp.; II-Tibouchina pulchra; III-Morta; IV-Eugenia brasiliensis; V-Psychotria sp2; VI-Solanum inaequale; VII-Roupala brasiliensis; VIII-Guatteria sp.; IX-Rapanea ferruginea; X-Nectandra sp.; XI-Hyeronima alchorneoides; XIIWeinmania sp.; XIII-Lauraceae 2; XIV-Euterpe edulis; XV-Cabralea canjerana.

Ocotea sp. (canelinha) IVC=13,38 e Tibouchina pulchra (jacatirão) IVC=12,62 ocupam o primeiro e o segundo lugares, respectivamente, enquanto a canelinha deve sua posição mais em função de sua densidade relativa ( $\mathrm{DeR}=7,77)$ do que à sua dominância relativa (DoR=5,6), com referência ao jacatirão nota-se que sua dominância relativa $(D o R=8,05)$ interfere mais do que sua densidade relativa (DeR=4,57) (FIGURA 3). Este aspecto conduz a T. pulchra, com área basal de $2,8 \mathrm{~m}^{2} / \mathrm{ha}$, a ocupar a primeira posição, com referência à dominância, dentre as quinze espécies que detêm os maiores valores, (FIGURA 4).

Com relação à Eugenia brasiliensis (grumixava) com IVC de 8,96 e IVI de 10,14, deve à sua dominância, DoR=7,66, o lugar 
assegurado dentre as cinco espécies primeiras colocadas, pois apresenta valores baixos de densidade e de freqüência relativas, 1,31 e 1,18, respectivamente não sendo referenciada entre as quinze espécies de valores mais elevados (FIGURAS 5 e 6).

Excetuando as árvores mortas, nota-se que as cinco espécies que atingem maiores áreas basais, compreendem a Tibouchina pulchra $\left(2,81 \mathrm{~m}^{2} / \mathrm{ha}\right)$, Eugenia brasiliensis $\left(2,68 \mathrm{~m}^{2} / \mathrm{ha}\right)$, Ocotea $\mathrm{sp} .\left(1,96 \mathrm{~m}^{2} / \mathrm{ha}\right)$, Psychotria sp2 $\left(1,58 \mathrm{~m}^{2} / \mathrm{ha}\right)$ e Solanum inaequale $\left(1,38 \mathrm{~m}^{2} / \mathrm{ha}\right)$ (FIGURA 4).

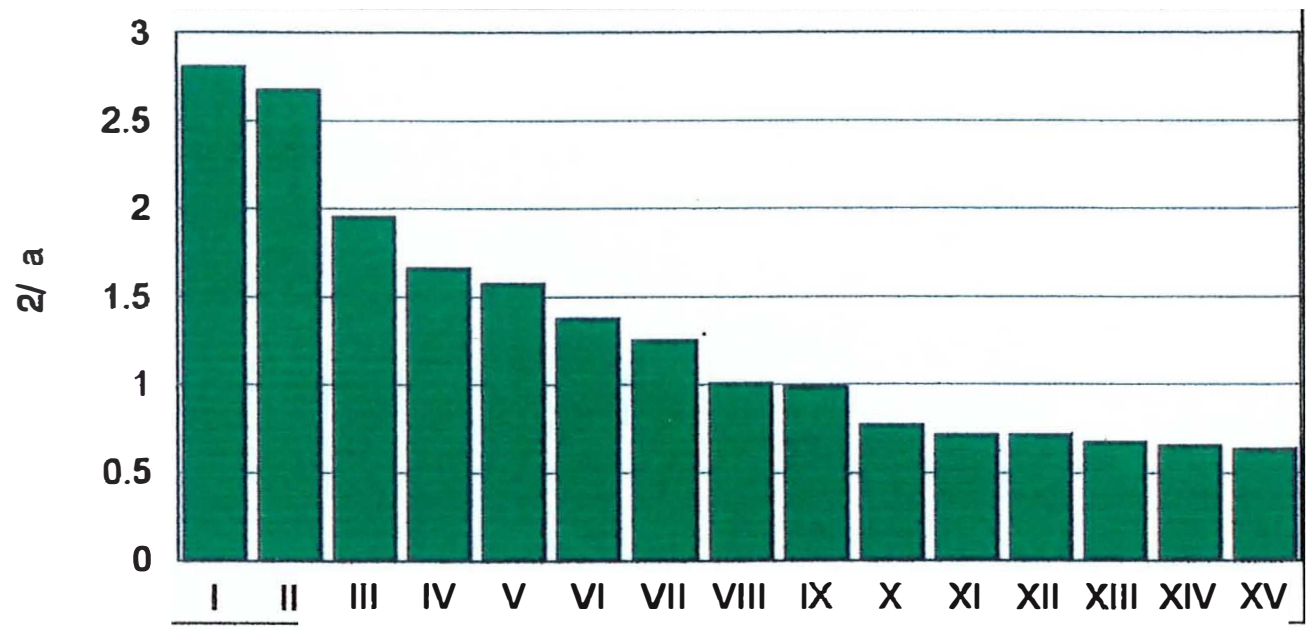

FIGURA 4 - As 15 espécies com maiores dominâncias em uma mata secundária no Parque Estadual de Carlos Botelho, SP. I-Tibouchina pulchra; II-Eugenia brasiliensis; IIIOcotea sp.; IV-Morta; V-Psychotria sp2; VI-Solanum inaequale; VII-Nectandra sp.; VIII-Lauraceae 2; IX-Roupala brasiliensis; X-Sclerolobium denudatum; XIWeinmania sp.; XII-Hymenaea sp.; XIII-Copaifera langsdorffii; XIV-Rapanea ferruginea; XV-Pterocarpus violaceus.

Euterpe edulis com IVC=3,15 (FIGURA 3) ocupa a décima quarta posição, dentre as espécies analisadas, ressaltando-se que seu IVI é da ordem de 6,22, isto é, décimo lugar. Esses valores alcançados são mais em função de sua freqüência e densidade, sexto e nono lugares, respectivamente (FIGURAS 5 e 6) pois em termos de dominância relativa 
$(D o R=0,6)$ não se encontra entre as 15 que se apresentam com os maiores valores caracterizando-a como uma população de indivíduos de porte menos desenvolvidos.

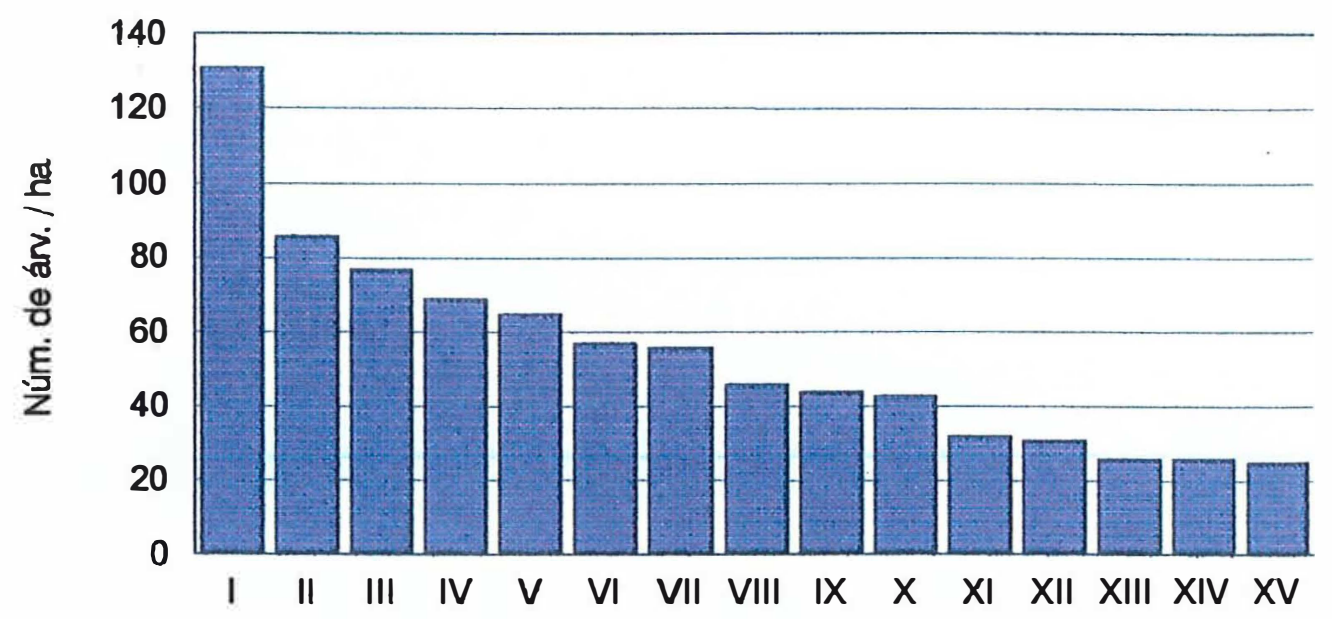

FIGURA 5 - As 15 espécies com maiores densidades em uma mata secundária no Parque Estadual de Carlos Botelho, SP. I- Ocotea sp.; II- Morta; III- Tibouchina pulchra; IV- Solanum inaequale; V- Psychotria sp2; VI-Roupala brasiliensis; VII-Guatteria sp.; VIII- Hyeronima alchorneoides; IX-Rapanea ferruginea; X- Euterpe edulis; XICabralea canjerana; XII- Jacaranda puberula; XIII- Amaioua sp.; XIV- Miconia theaezans; XV-Weinmania sp.

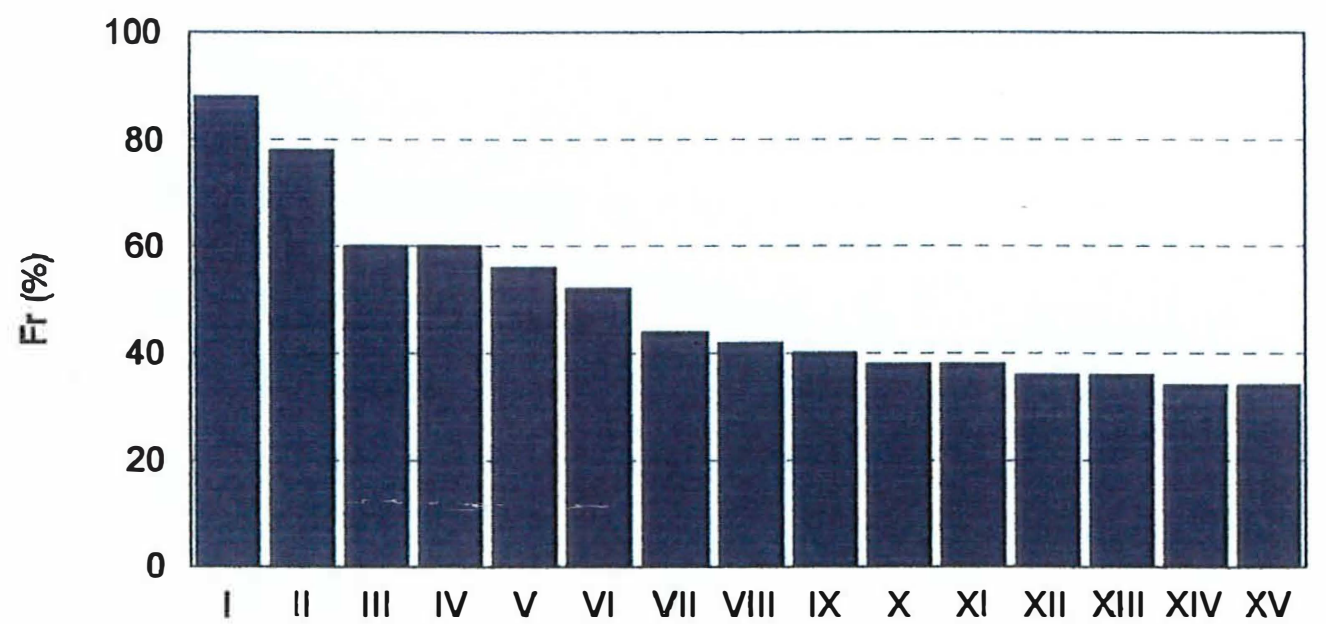

FIGURA $6^{\circ}$ - As 15 espécies com maiores frequências em uma mata secundária no Parque Estadual de Carlos Botelho, SP. I- Ocotea sp.; II- Morta; III- Psychotria sp2; IVGuatteria sp.; V-Roupala brasiliensis; VI- Euterpe edulis; VII- Tibouchina pulchra; VIII- Solanum inaequale IX- Cabralea canjerana; $X$ - Rapanea ferruginea; XIAmaioua sp.; XII- Hyeronima alchorneoides; XIII- Cordia sp.; XIV- Weinmania sp.; $X V$ - Pouteria torta. 
Dias (1993) na mesma área, considerando DAP a partir de 10 $\mathrm{cm}$, encontrou para o palmito um $|\mathrm{V}|=1,20$. No núcleo Sete Barras, Parque Estadual de Carlos Botelho, Negreiros (1982) observou um $|V|=19,01$ para Euterpe edulis e Negreiros et al. (1995) detectaram, para a mesma essência, um $I V I=32,87$ e um IVC=27,06, sendo considerada a espécie mais importante na comunidade estudada , a qual se apresenta pouco perturbada. $O$ que vem de encontro à observação de Mantovani (1993) assinalando que nas áreas mais preservadas de florestas ombrófilas densas no estado de São Paulo, E. edulis situa-se como das mais importantes na sua estrutura, embora seja típica de sub-bosque.

Cabralea canjerana com IVI=5,48 e IVC=3,11 ocupa o décimo terceiro lugar, concordando com Reitz et al. (1983) que informam sobre a ocorrência dessa espécie em áreas de capoeira e capoeirão, tanto em floresta atlântica como em florestas estacionais apresentando regeneração agressiva. Com 32 indivíduos amostrados essa espécie tem freqüência relativa de 2,36, densidade relativa de 1,90 e dominância relativa de 1,21.

Comparando-se a ordenação das espécies relacionadas em ordem decrescente de IVI e IVC e atendo-se às 15 que alcançaram os maiores valores, observa-se que Ocotea sp. (canelinha) e Tibouchina pulchra (jacatirão) mantiveram-se nos primeiro e segundo lugares, para os dois índices. Psychotria sp2 (erva-de-anta), na quarta posição (IVI) passa para a quinta posição (IVC).

Eugenia brasiliensis (grumixava) em sexto lugar do IVI, galga posição de maior destaque com relação ao IVC, ascendendo ao quarto lugar. Solanum inaequale passa da quinta posição de IVI para a sexta em IVC. 
Mantendo-se nas sétima, oitava, nona e décima terceira posições, nos dois índices considerados encontram-se: Roupala brasiliensis (carne-de-vaca), Guatteria sp. (pindaúva), Rapanea fernuginea (capororoca-vermelha) e Euterpe edulis (palmito).

Hyeronima alchomeoides (urucurana) e Weinmania sp. (cupiúva) classificadas em décimo primeiro e décimo segundo lugares mantêm suas posições, com relação ao IVC.

De modo geral, considerando as 15 espécies analisadas em termos dos índices de valor de importância (IVI) e de cobertura (IVC) há espécies que se mantém nas mesmas posições, algumas têm suas posições invertidas e outras ocupam posições diferenciadas. As exceções ficam para Pouteria torta (guapeva) referenciada entre as 15 de maiores IVI, décima quinta posição, não se encontra entre as de maiores IVC e a Lauracea 2 (nhutinga) relacionada entre as de maiores IVC, décimo quarto lugar, não se encontra entre as de maiores IVI.

Na FIGURA 7 Eugenia brasiliensis (grumixava), em quinto lugar, e Nectranda sp. (canela amarela), em décimo lugar, se destacam por apresentarem maiores porcentagens de dominância em relação às suas densidade e freqüência, demonstrando que na comunidade estudada estas espécies são representadas por árvores de maior porte. Enquanto Guatteria sp. (pindaúva) ocupando o nono lugar e Euterpe edulis em décimo terceiro lugar se destacam com maiores porcentagens de freqüência caracterizando-se como espécies com distribuição mais regular na comunidade estudada. 


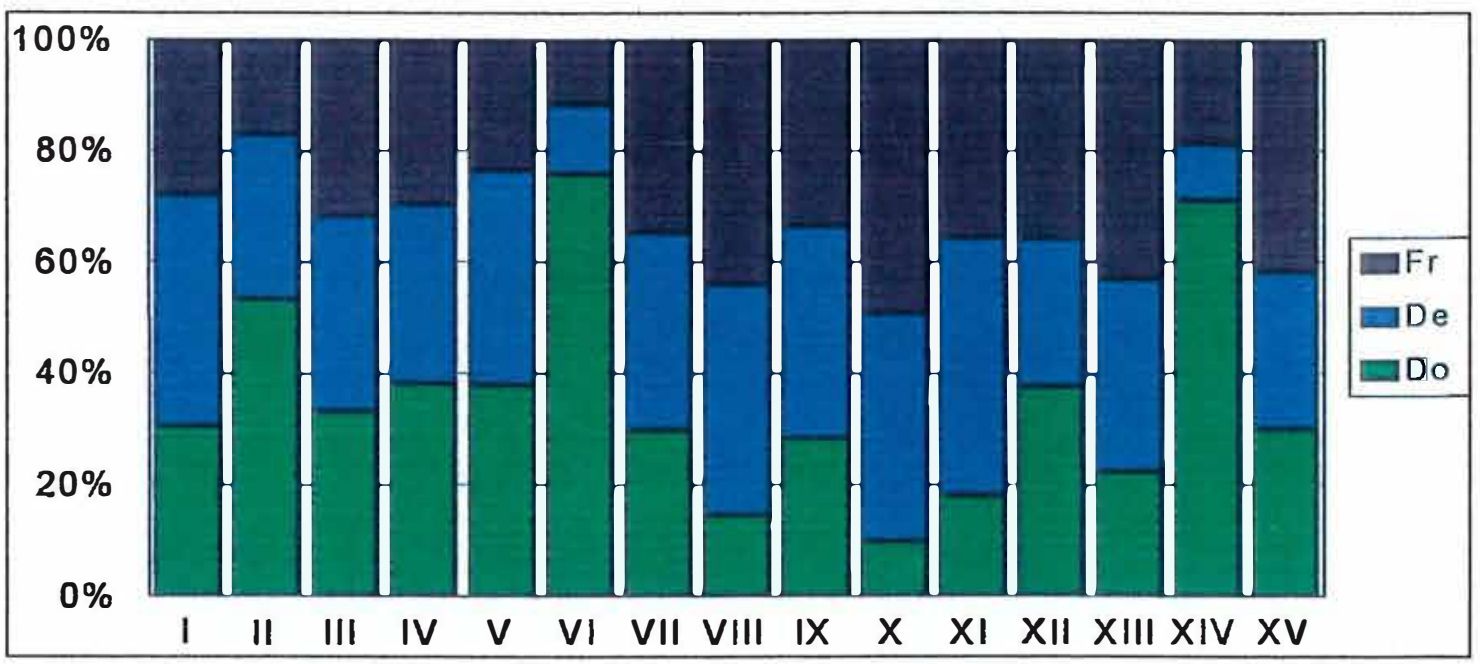

FIGURA 7 - Porcentagens de dominância, densidade e freqüência relativas na composição do IVI dentre as 15 mais importantes em uma mata secundária no Parque Estadual de Carlos Botelho, SP. I- Ocotea sp.; II- Tibouchina pulchra; III- Morta; IV- Psychotria sp2; V- Solanum inaequale; VI- Eugenia brasiliensis; VII- Roupala brasiliensis; VIIIGuatteria sp.; IX- Rapanea ferruginea; X- Euterpe edulis; XI- Hyeronima alchomeoides; XII- Weinmania sp.; XIII- Cabralea canjerana; XIV- Nectandra sp.; XV-Pouteria torta.

\subsection{2 Árvores Mortas}

O número de árvores mortas (86) representa $5,10 \%$, do total de árvores amostradas. As árvores mortas ocupam a terceira posição no IVI $(14,48)$, importância essa devida aos valores de densidade relativa (DeR $=5,10 \%)$, de dominância relativa (DoR=4,77\%) e freqüência ( $\mathrm{FrR}=4,61 \%)$, que mantém, praticamente, as mesmas proporções.

Para as florestas brasileiras os dados sobre a fitomassa morta, ainda são escassos (Martins, 1979; Cavassam et al., 1984 e Negreiros et al., 1995). Vasconcelos (1992) assinala que o lugar de destaque das árvores mortas sugerem ser um fator comum na dinâmica das fitocenoses.

Dentre os fatores de ordem natural que atuam na mortalidade das árvores destacam-se a senescência (Martínez-Ramos, 1985), patógenos e ventos fortes (Martins,1979). Quanto aos fatores provocados 
por intervenção antrópica salientam-se a exploração seletiva e o corte raso. A área sofreu exploração até o ano de 1941 quando, por força da legislação pertinente, foi preservada como Reserva Estadual passando, posteriormente, à categoria de Parque Estadual.

Em estudos desenvolvidos por vários autores, considerando diferentes tipos de florestas e/ou diversos fatores que atuam sobre os níveis de mortalidade das árvores, os dados obtidos apresentam resultados variados. Costa (1992) encontrou uma proporção de $0,2 \%$ de árvores mortas em mata mesófila semidecidua, localizada em Piracicaba, SP. No estudo de floresta residual, também no interior do estado de São Paulo, Martins (1979) detectou 7,1\% de árvores mortas.

A proporção encontrada por De Vuono (1985) foi de 11,5\%, numa área de transição entre mata atlântica e floresta semidecídua de planalto, enquanto Rodrigues (1986) assinalou 7,59\% de árvores mortas na mata mesófila semidecidua da serra do Japi (SP) e Leitão Filho et al.(1993) mencionou o valor de 14,67\% para mata atlântica, em Cubatão.

\subsubsection{Classes de IVI}

A TABELA 3 mostra a distribuição do número de espécies e individuos em classes de IVI, conforme procedimento adotado por Barros (1986).

TABELA 3 - Distribuição do número de espécies e individuos em classes de IVI.

\begin{tabular}{|c|c|c|c|}
\hline Classe de IVI & Amplitude & $\begin{array}{c}\text { Número de } \\
\text { Espécies }\end{array}$ & $\begin{array}{c}\text { Número de } \\
\text { Individuos }\end{array}$ \\
\hline I & $\mathrm{IVI}<1,00$ & 48 & 105 \\
\hline II & $1,00 \leq|\mathrm{V}|<4,00$ & 39 & 392 \\
\hline III & $4,00 \leq \mathrm{VI}<15,00$ & 16 & 583 \\
\hline IV & $\mid \mathrm{VI} \geq 15,00$ & 2 & 208 \\
\hline TOTAL & & 105 & 1288 \\
\hline
\end{tabular}


Salienta-se que o valor total de 1288 indivíduos não está considerando o número de árvores mortas e, também as não identificadas no campo, isto é, as desconhecidas.

O maior número de espécies está concentrado nas classes I e II de IVI , com valores de IVI mais baixos, na maioria são espécies de baixa densidade populacional. Neste estudo estas espécies representam $45,7 \%$ e $37,3 \%$, respectivamente, do total de espécies amostradas, sendo que a diversidade da floresta tropical se deve, basicamente à essas espécies.

No entanto, as classes de IVI mais elevados abrangem maior número de indivíduos, desta forma são estas espécies mais abundantes, compreendidas nas classes III e IV, que caracterizam fisionomicamente a floresta.

Considerando as 1685 árvores, no hectare amostrado, convêm destacar o número de espécies e morfo-espécies representadas, apenas por um individuo, o que Ihes confere, de acordo com Martins (1979), um caráter de raridade. Essas espécies constituem 1,1\% do total dos indivíduos amostrados e 17,92\% do total de espécies amostradas.

Martins (1979) acentua que nas florestas atlânticas a porcentagem de espécies raras varia de 9,23 a $39,52 \%$.

Warming (1908) citado por Martins (1991) já chamava a atenção para o fato de que na floresta nativa, muitas espécies arbóreas apresentam um número bastante reduzido de indivíduos. Cain et al. (1956) confirmaram essa colocação. 


\subsubsection{Diversidade e Equabilidade}

Whittaker (1965) citado por Dias (1993) considera que podese medir a diversidade de espécies tendo por base o número de espécies, em unidades de amostragem cuja intensidade deve ser suficiente para incluir, também as espécies com pequeno número de indivíduos.

$O$ índice de diversidade de Shannon obtido para a comunidade estudada foi de $H^{\prime}=3,66$ e a equabilidade, $J^{\prime}=0,78$.

$O$ valor de $H^{\prime}=3,66$ está dentro da amplitude de valores de $H^{\prime}$ detectados para as florestas atlânticas, por Martins (1991), que abrangem de 2,20 a 4,07.

Baitello et al. (1992) detectaram $\mathrm{H}^{\prime}=4,13$ em um trecho da serra da Cantareira (SP), amostrando DAP minimo de $10 \mathrm{~cm}$.

Todavia, Mantovani (1993) obteve valores de $H^{\prime}=4,19$ para a floresta atlântica, na Juréia (SP) para árvores a partir de, aproximadamente, $9,55 \mathrm{~cm}$ de DAP, sendo o maior valor de diversidade encontrado, até o momento, para as florestas no estado de São Paulo.

Já numa área alterada do vale do Rio Moji em Cubatão (SP), Leitão Filho (1993) obteve índice de diversidade de 2,14 e no vale do Rio Pilões, também em Cubatão, em três locais estudados, os valores de diversidade determinados pelo índice de Shannon foram de: 3,77; 3,92 e 3,64 .

Os valores mais elevados de diversidade para florestas tropicais, foram os encontrados por Knight (1975) citado por Martins (1991), variando de 3,83 à 5,85, para espécies arbóreas com $2,5 \mathrm{~cm}$ ou mais de DAP, nas florestas da ilha de Barro Colorado, Panamá. 
Vale ressaltar que Pagano et al. (1987) e Martins (1991) chamam a atenção para o fato de que os valores obtidos pelos índices são influenciados pela área de amostragem e Mantovani (1993) refere-se à influência que exerce o critério de inclusão dos indivíduos a serem amostrados.

Com relação ao índice de Shannon, Dias (1993) detectou uma pequena sensibilidade do índice, ao aumentar o número de pontos de amostragem, no Parque Estadual de Carlos Botelho(SP), com tendência a se estabilizar a partir de um determinado valor.

A equabilidade $J^{\prime}=0,78$ evidencia baixa uniformidade na distribuição da abundância entre as populações amostradas, influenciando no valor da diversidade, ou seja, $\mathrm{H}^{\prime}$.

$O$ quociente de mistura $(Q M)$ revelou um valor de $Q M=0,06$ ou 1:15, isto é, aproximadamente, uma espécie para cada 15 árvores amostradas. Lamprecht (1990) salienta que O QM representa uma indicação da intensidade de mistura e que os valores dependem do diâmetro mínimo e do tamanho da amostra. $O$ autor cita que em alguns trechos de floresta clímax os valores de QM podem chegar a 1:3, mä em média ficam em tomo de 1:7.

\subsubsection{Classes de Diâmetros}

É apresentado a seguir a distribuição diamétrica das espécies com mais de 30 árvores amostradas, além da distribuição diamétrica das árvores mortas. Ocotea sp. (FIGURA 8) concentra maior número de indivíduos na primeira classe, apresentando a partir dessa classe diamétrica uma freqüência decrescente até a quarta classe e estabilizando-se a seguir, com a presença de indivíduos jovens e 
maduros. Esta espécie encontra condições favoráveis à sua instalação, reprodução e permanência na área estudada.

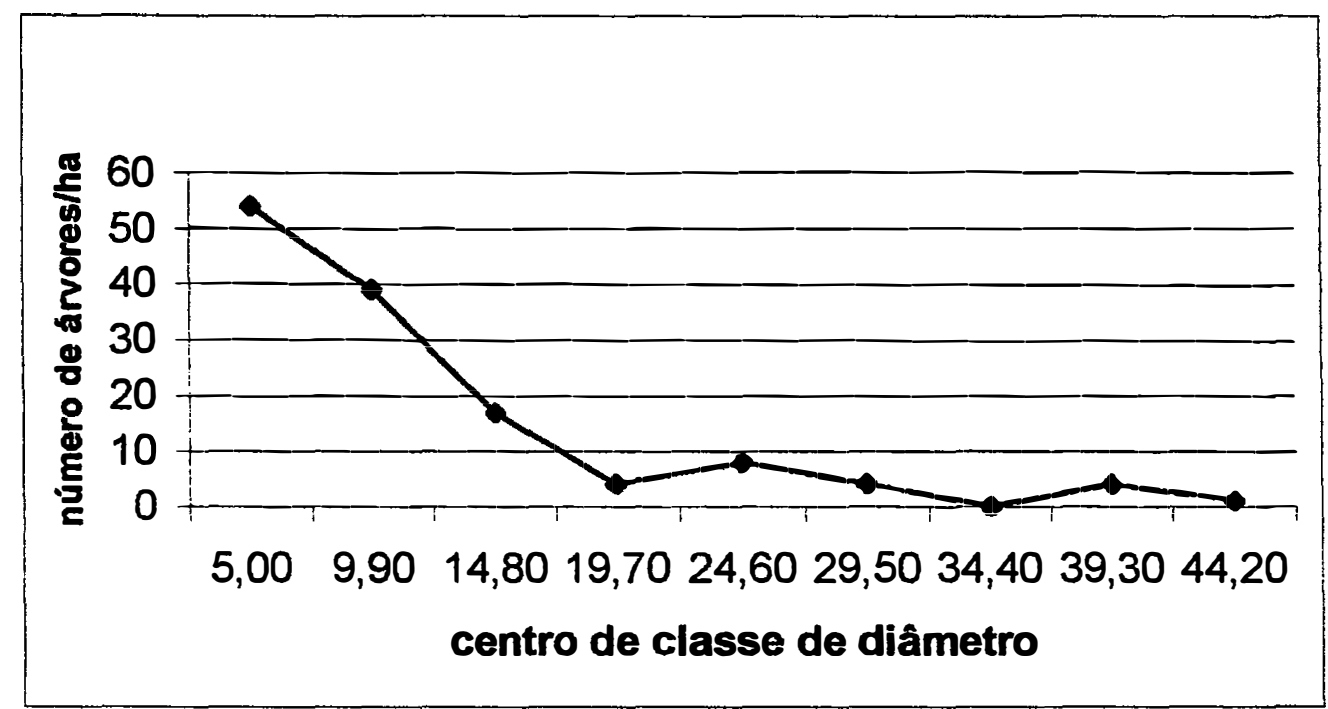

FIGURA 8 - Distribuição diamétrica de Ocotea sp. em uma mata secundária no Parque Estadual de Carlos Botelho, SP.

A maioria das espécies analisadas concentra maior número de indivíduos na primeira ou segunda classe diamétrica, exceto Tibouchina pulchra (FIGURA 9). T. pulchra e Rapanea ferruginea (FIGURA 10) são espécies pioneiras, intolerantes à sombra, que não se regeneram em locais onde o dossel se encontra mais fechado. Reitz et al. (1978) acentuam que na área do vale do Itajaí, $R$. fernuginea em determinado estádio de desenvolvimento da vegetação secundária, constitui-se em uma das espécies dominantes dos capoeirões. Afirmam, ainda, sua ocorrência nas capoeiras das encostas da região da mata pluvial da encosta atlântica sul brasileira. Enquanto Carvalho (1994) acentua que a espécie pode crescer sob a sombra. 


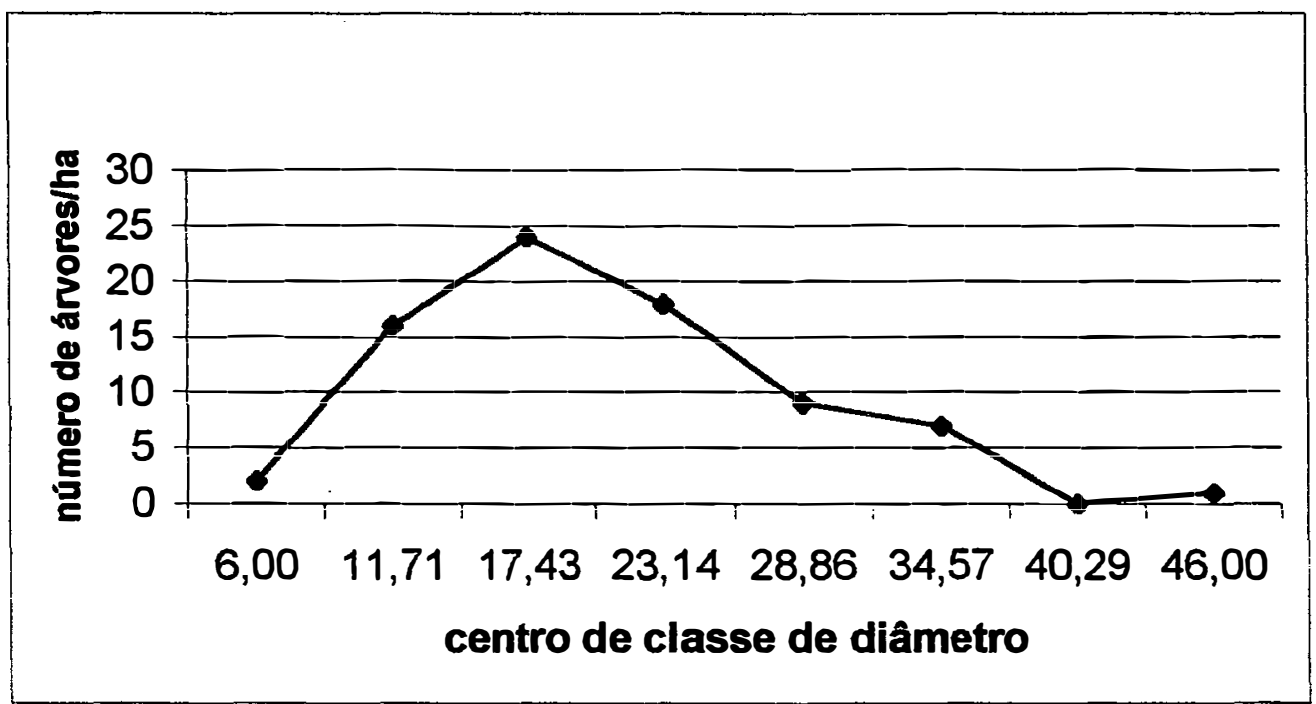

FIGURA 9 - Distribuição diamétrica de Tibouchina pulchra em uma mata secundária no Parque Estadual de Carlos Botelho, SP.

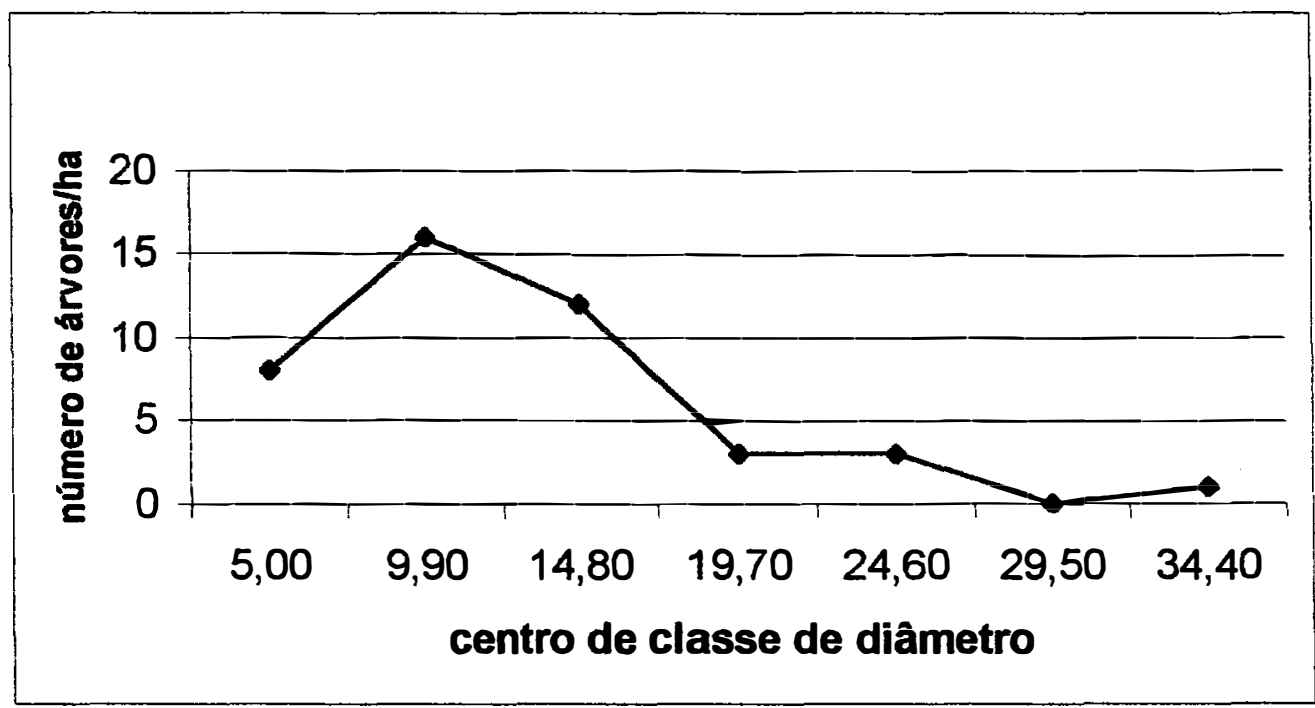

FIGURA 10 - Distribuição diamétrica de Rapanea femuginea em uma mata secundária no Parque Estadual de Carlos Botelho, SP.

Para Solanum inaequale (FIGURA 11) era de se esperar comportamento semelhante aos da $T$. pulchra e da $R$. ferruginea, todavia, a espécie apresenta maior número de indivíduos na primeira classe. 


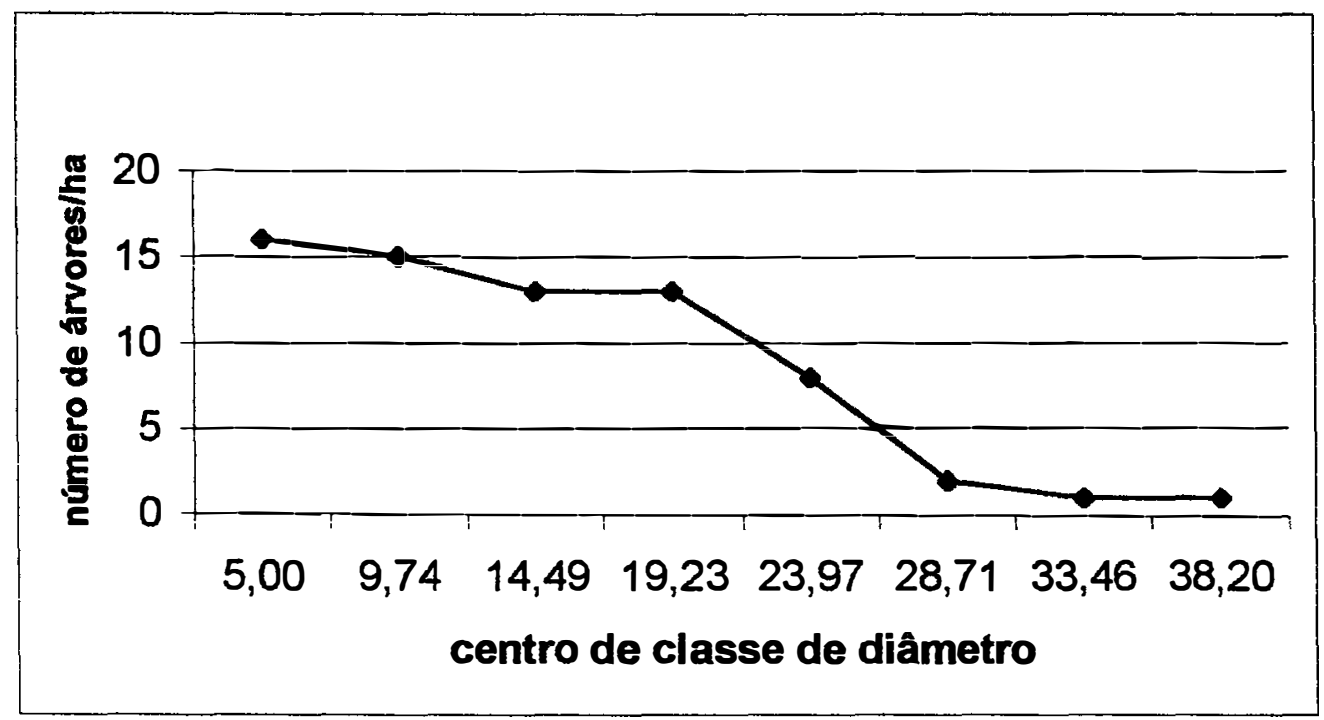

FIGURA 11 - Distribuição diamétrica de Solanum inaequale em uma mata secundária no Parque Estadual de Carlos Botelho, SP.

A distribuição dos indivíduos mortos (FIGURA 12), com maior predominância nas primeira e segunda classes diamétricas seguem o padrão mencionado por White \& Harper (1970) citados por Hutchings (1986). Estes autores afirmam ser típico a concentração da mortalidade nas classes diamétricas de menores tamanhos. Resultados semelhantes foram detectados por Negreiros et al. (1995) em Sete Barras, atingindo os indivíduos mortos até à sexta classe diamétrica, 50 à $59 \mathrm{~cm}$ de DAP. 


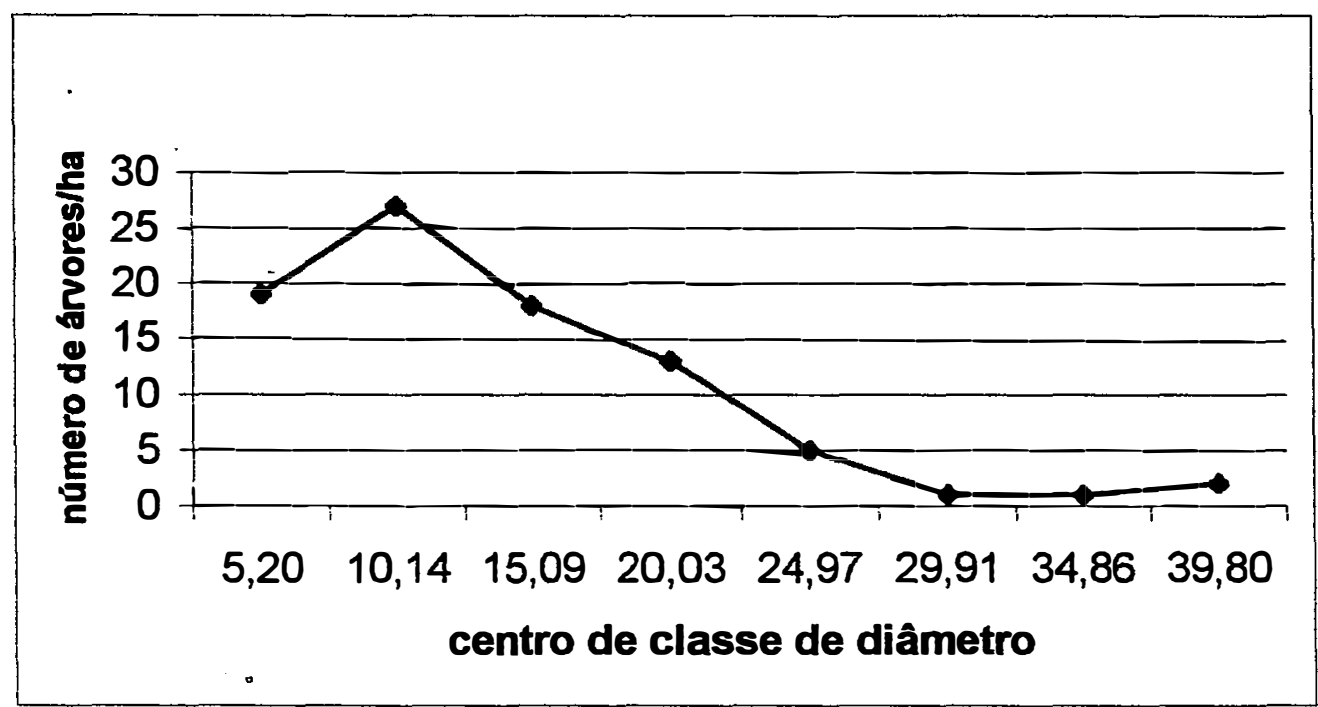

FIGURA 12 - Distribuição diamétrica de árvores mortas em uma mata secundária no Parque Estadual de Carlos Botelho, SP.

Psychotria sp2. (FIGURA 13) embora apresente maior concentração de indivíduos na primeira classe diamétrica mantêm individuos até à oitava classe. É considerada secundária inicial e sua população se compõe de indivíduos de porte mais desenvolvidos.

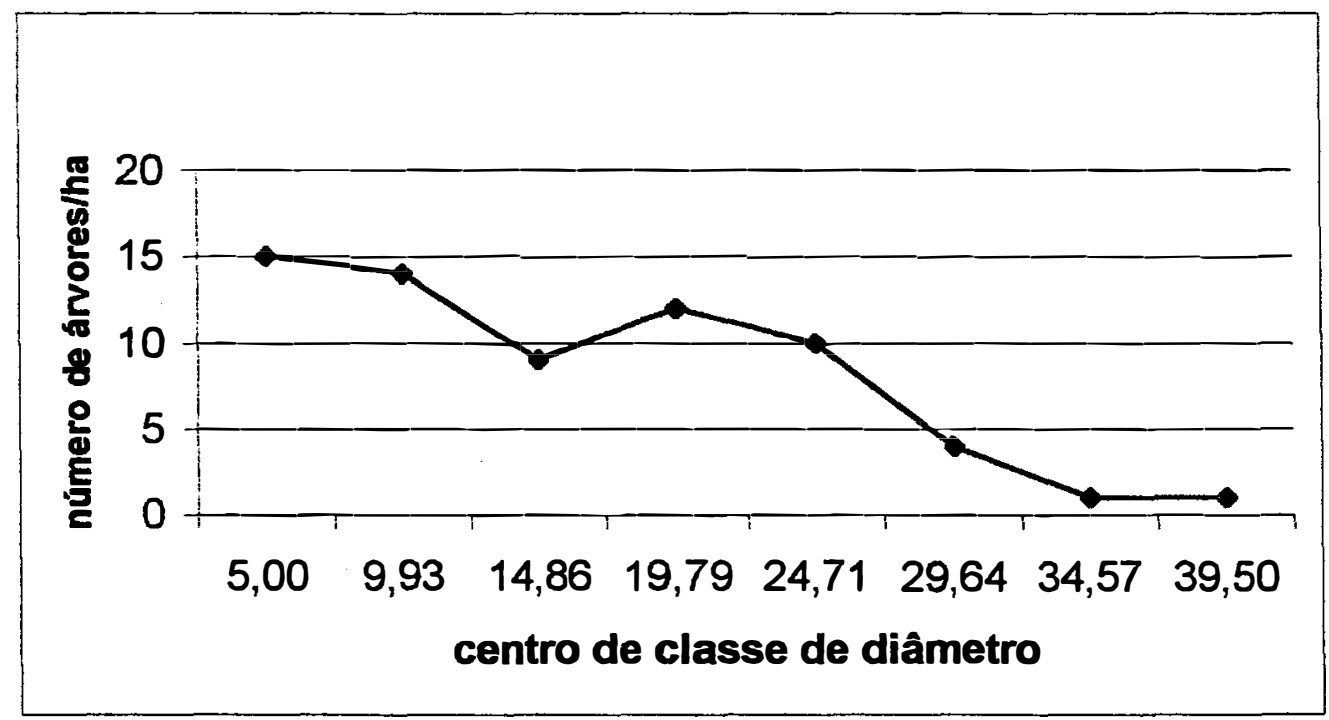

FIGURA 13 - Distribuição diamétrica de Psychotria sp2 em uma mata secundária no Parque Estadual de Carlos Botelho, SP. 
Cabralea canjerana (FIGURA 15) apresentou uma distribuição irregular, enquanto as espécies Guatteria sp., Jacaranda puberula, Hyeronima alchomeoides e Roupala brasiliensis (FIGURAS 14, 16, 17 e 18) tem comportamentos semelhantes com predominância de maior número de indivíduos na segunda classe, diminuindo nas classes subsequentes. Leitão Filho et al. (1993) assinalam para Cabralea canjerana a categoria de espécie secundária tardia no processo de sucessão e para Hyeronima alchomeoides a categoria de pioneira. Para Carvalho (1994) Roupala brasiliensis é uma espécie secundária tardia e Lorenzi (1992) a coloca como característica da mata pluvial da planície e encosta atlântica, apresentando freqüência expressiva.

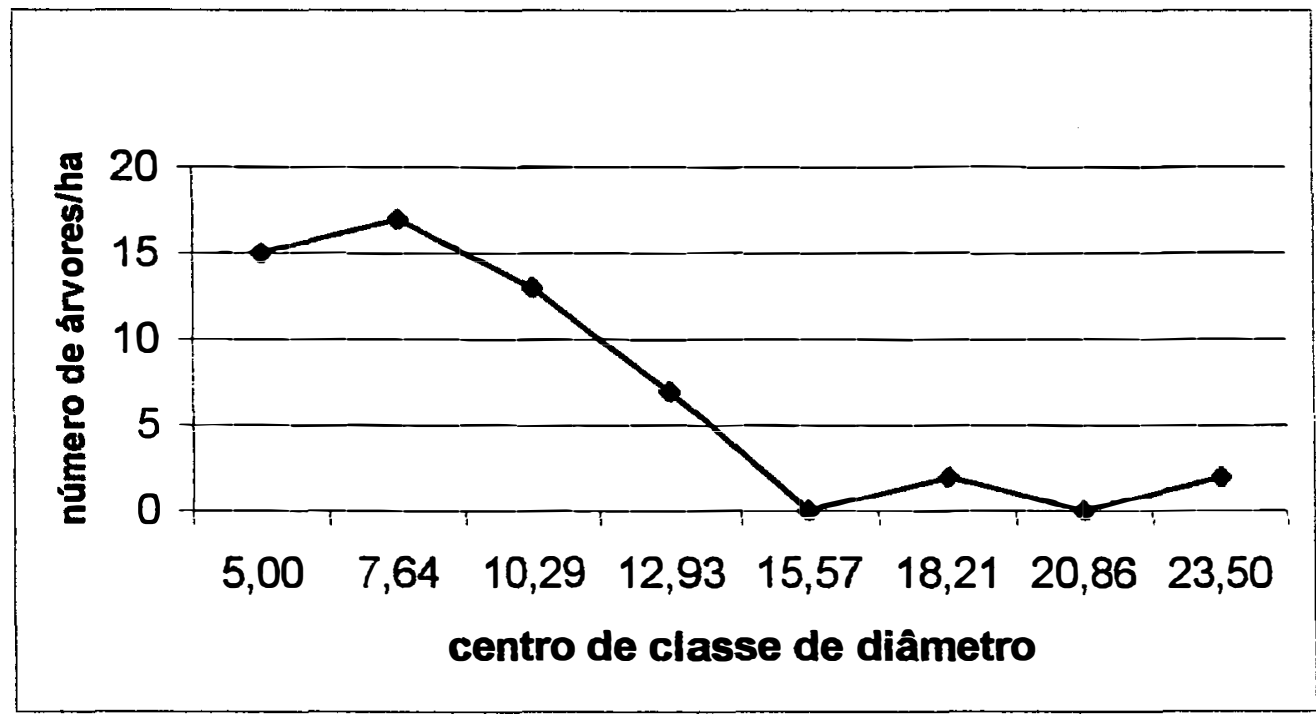

FIGURA 14 - Distribuição diamétrica de Guatteria sp. em uma mata secundária no Parque Estadual de Carlos Botelho, SP. 


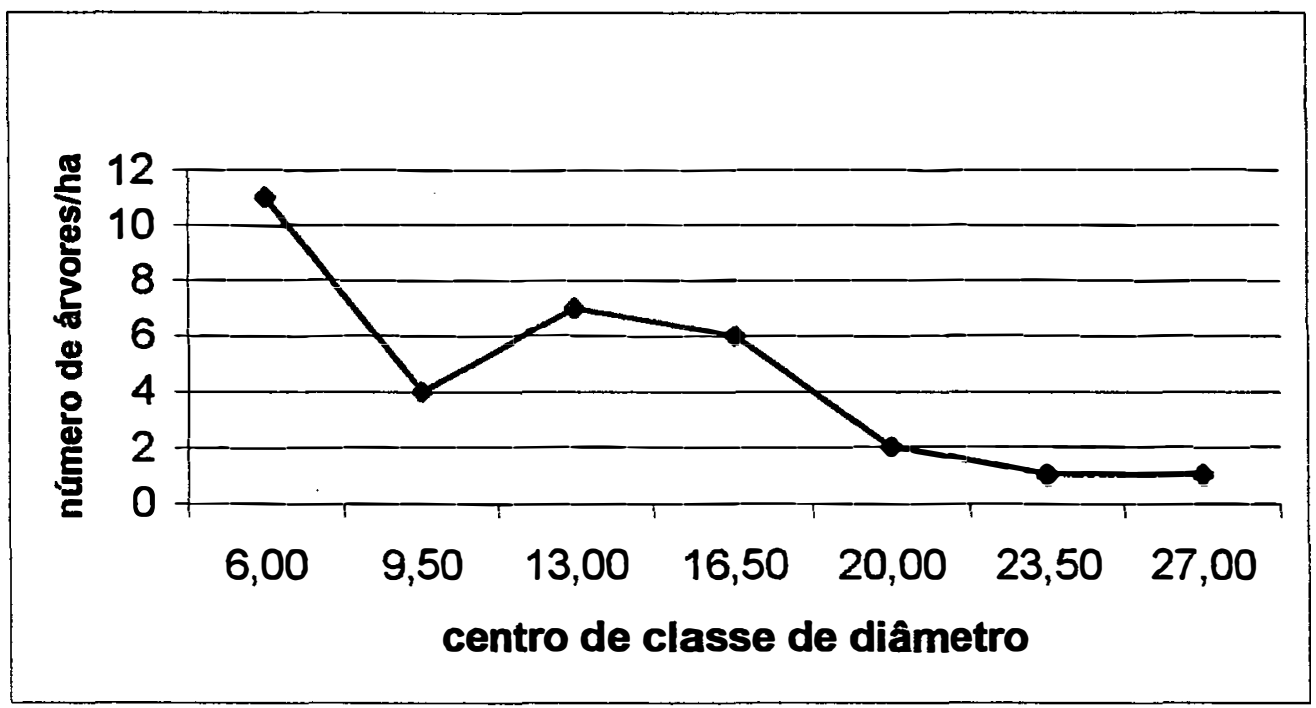

FIGURA 15 - Distribuição diamétrica de Cabralea canjerana em uma mata secundária no Parque Estadual de Carlos Botelho, SP.

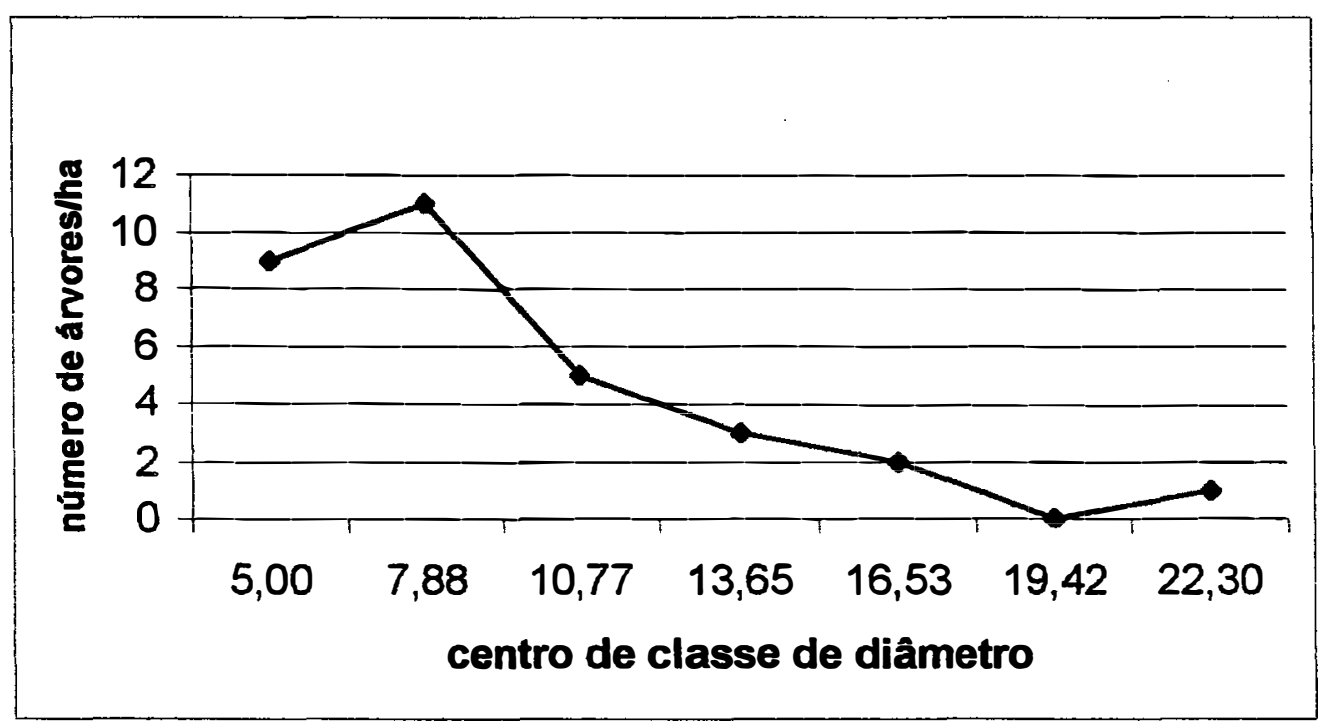

FIGURA 16 - Distribuição diamétrica de Jacaranda puberula em uma mata secundária no Parque Estadual de Carlos Botelho, SP. 


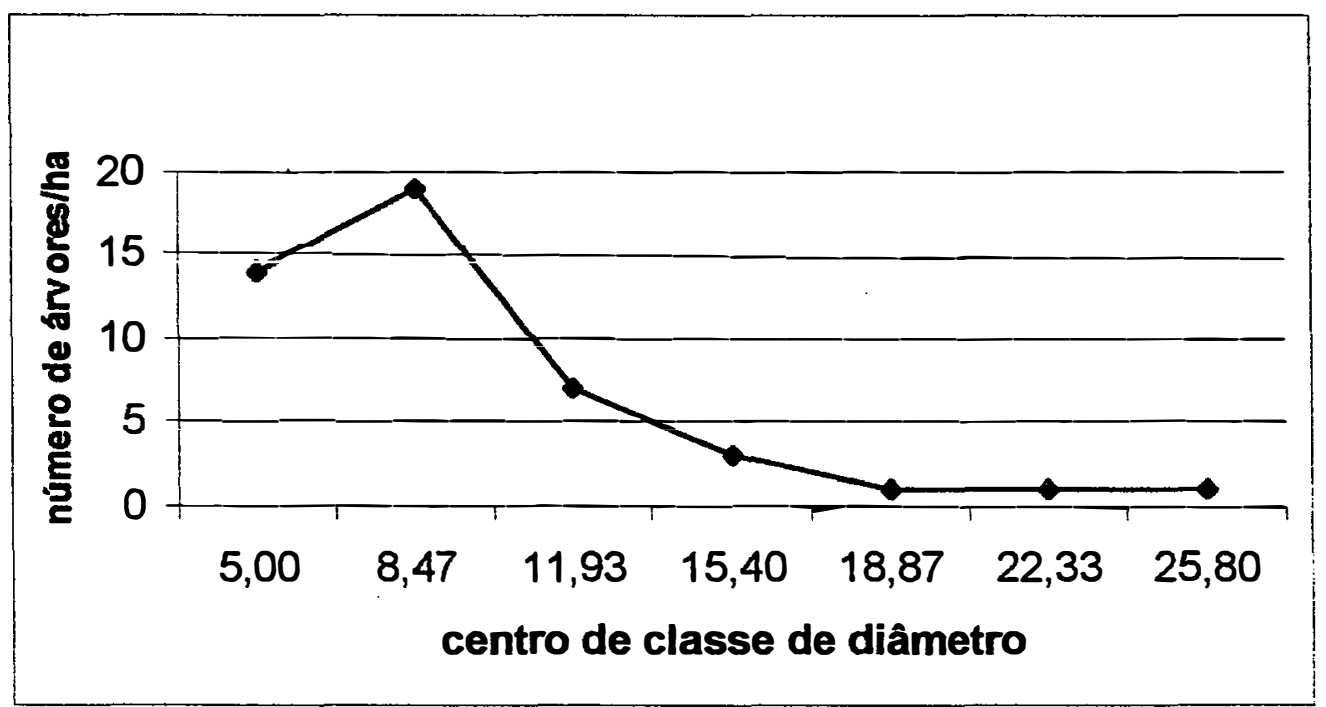

FIGURA 17 - Distribuição diamétrica de Hyeronima alchorneoides em uma mata secundária no Parque Estadual de Carlos Botelho, SP.

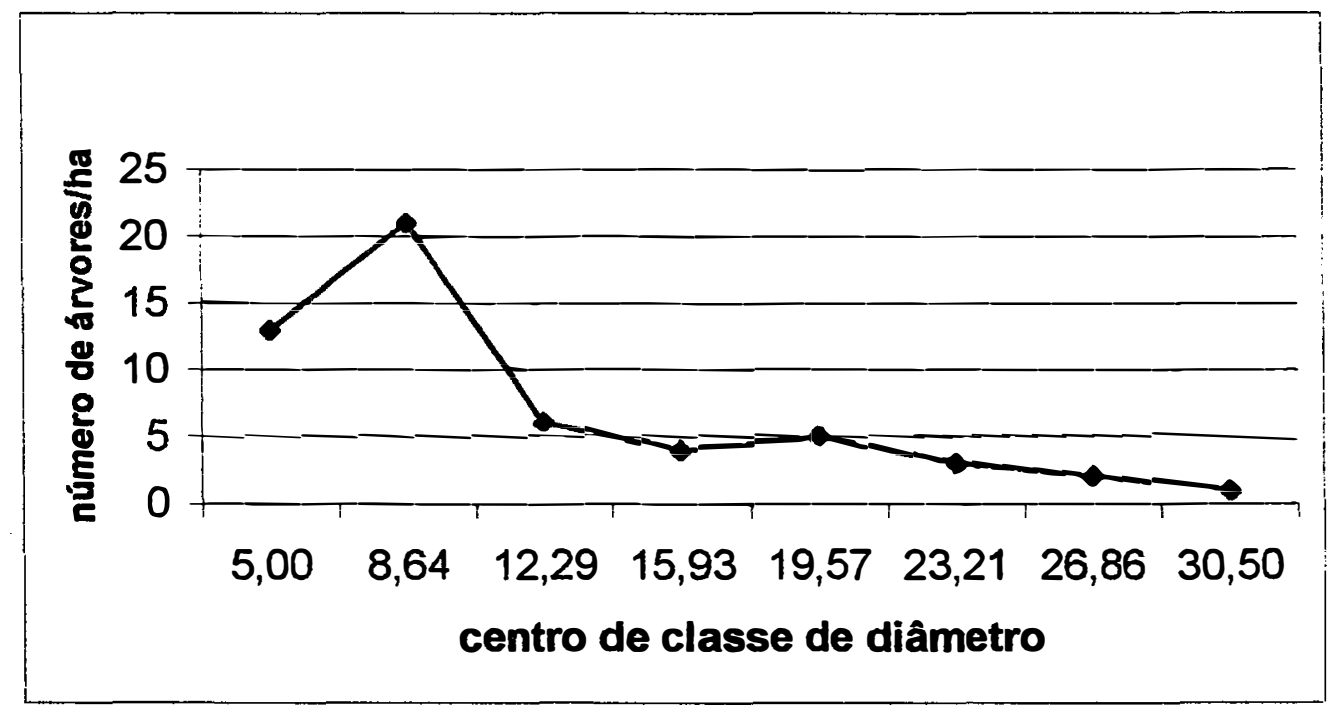

FIGURA 18 - Distribuição diamétrica de Roupala brasiliensis em uma mata secundária no Parque Estadual de Carlos Botelho, SP. 
Euterpe edulis (FIGURA 19) se distribui de modo decrescente, aumentando relativamente a freqüência nas classes maiores. Tem boa capacidade de regeneração na área, com predominância de exemplares mais jovens. Negreiros et al. (1995) obtiveram resultados semelhantes para Euterpe edulis, em Sete Barras, não ultrapassando seus indivíduos $20 \mathrm{~cm}$ de DAP. Reiteram ser a espécie dominante no sub-bosque da floresta pluvial tropical do sul do Brasil. Mantovani (1993) assinala o caráter indiferente dessa espécie quanto à necessidade de.luz, enquanto Leitão Filho et al. (1993) consideram-na secundária inicial.

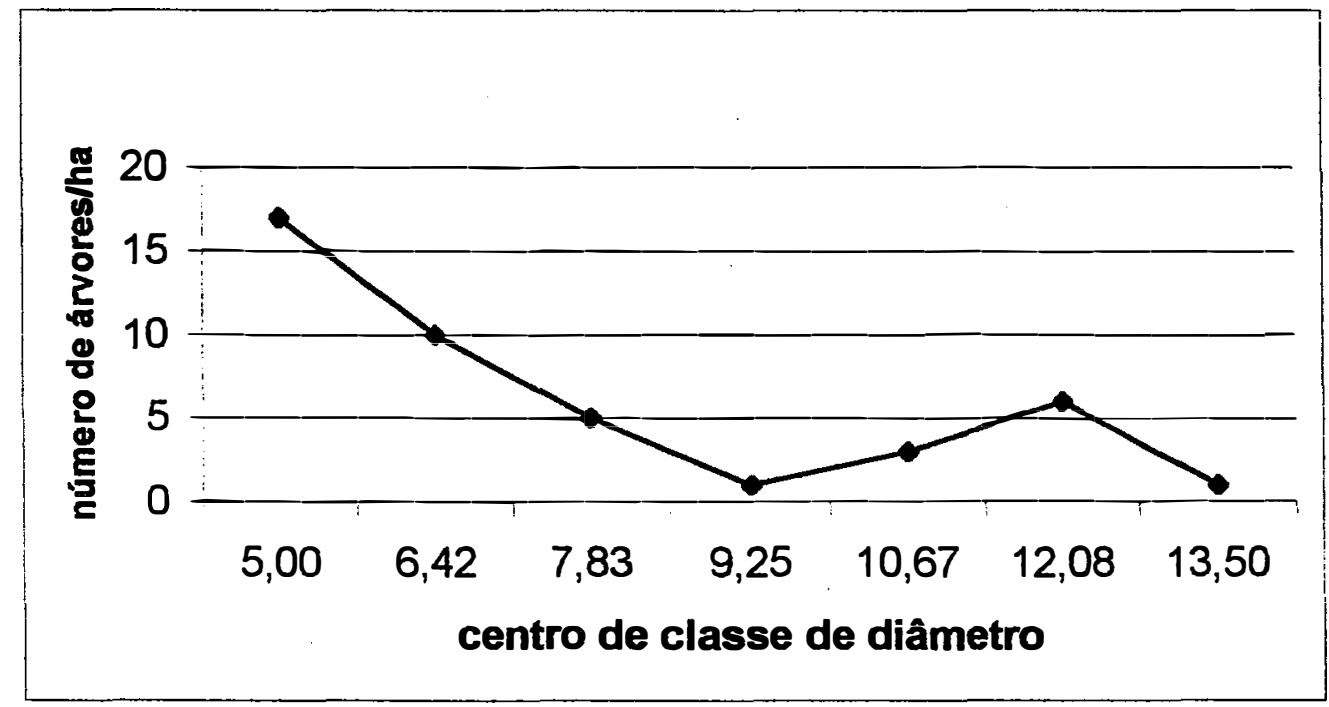

FIGURA 19 - Distribuição diamétrica de Euterpe edulis em uma mata secundária no Parque Estadual de Carlos Botelho, SP.

As espécies analisadas demonstram que o padrão de distribuição das espécies diferem entre si. Com exceção de Tibouchina pulchra, as demais espécies mantém a mesma característica de maior concentração de indivíduos na primeira ou segunda classe diamétrica. 
Os aspectos evidenciados refletem processos de adaptação das espécies, variações nos niveis de recrutamento e de sobrevivência que condicionam diferentes estruturas nas populações de plantas.

Batista (1989) acentua que as espécies com distribuição "J invertido" vão sendo substituídas por espécies com distribuição de curvatura mais suave, tendendo quase a uma reta. Refere-se ainda à forma " $\mathrm{J}$ invertido" como sendo relacionada a regeneração contínua, e a forma normal assimétrica a um padrão de regeneração descontínua. Pires (1976) e Knight (1975) citados pelo autor atribuem o padrão descontínuo às espécies intolerantes e a regeneração contínua às espécies tolerantes.

Hubbell e Foster (1987) denominam de distribuições "senis" quando tem relativamente poucas plantas jovens por adulto, enquanto distribuições com a forma "J invertido" são distribuições "jovens", de espécies tolerantes e que correspondem a muitas plantas jovens por adulto.

Tais classificações podem ser importantes, revelando muitos aspectos sobre a ecologia das espécies, no entanto os resultados aqui encontrados mostram que há grande variação espacial e temporal na estrutura de populações de plantas. Estes aspectos podem estar relacionados ao padrão de regeneração ou aos requisitos de luz ou, ainda, à etapa da sucessão na qual as espécies se encontram.

\subsection{Tamanho e número de parcelas}

4.2.1 Estimativas para a floresta a partir da área basal e da densidade

Para cada uma das cinco unidades amostrais, contendo 10 subparcelas cada uma e de acordo com a metodologia, calculou-se a estimativa de $\rho$. As Tabelas 4 e 5 apresentam os resultados da análise de 
variância, necessária para a obtenção do coeficiente de correlação intraclasse $\rho$. Os parâmetros utilizados foram: densidade de árvores por subparcela e área basal por subparcela, de acordo com a Tabela 6.

TABELA 4 - Quadro de análise de variância para estimativa de $\rho$ a partir da área basal por subparcela $\left(\mathrm{m}^{2} /\right.$ subparcela de $\left.200 \mathrm{~m}^{2}\right)$.

\begin{tabular}{cccc}
\hline Causa de Variação & G. L. & S.Q. & Q. $\mathbf{M .}$ \\
\hline Entre Parcelas & 4 & $\mathbf{0 , 2 2 7 0 9}$ & 0,05677 \\
Entre Subparcelas & 45 & 3,39511 & 0,07545 \\
\hline Total & 49 & 3,6222 & \\
\hline
\end{tabular}

TABELA 5 - Quadro de análise de variância para estimativa de $\rho$ a partir da densidade de árvores ( $\mathrm{n} / \mathrm{subparcela}$ de $200 \mathrm{~m}^{2}$ ).
Causa de Variação
G. L.
S.Q.
Q. M.

\begin{tabular}{cccc}
\hline Entre Parcelas & 4 & 918,6 & 229,65 \\
Entre Subparcelas & 45 & 4001,9 & 88,93 \\
\hline Total & 49 & $4.920,5$ & \\
\hline
\end{tabular}

TABELA 6 - Estimativas de área basal $\left(\mathrm{m}^{2} / \mathrm{ha}\right)$ e densidade de árvores (n/ha) por subparcela numa mata secundária do Parque Estadual de Carlos Botelho (SP).

\begin{tabular}{cccc}
\hline PARCELA & SUBPARCELA & ÁREA BASAL(m2/ha) & DENSIDADE(n/ha) \\
\hline 1 & 1 & 44,24 & 1650 \\
1 & 2 & 43,26 & 1550 \\
1 & 3 & 16,09 & 1200 \\
1 & 4 & 44,08 & 2000 \\
1 & 5 & 45,00 & 2350 \\
1 & 6 & 34,54 & 1500 \\
1 & 7 & 44,92 & 1200 \\
1 & 8 & 35,35 & 2500 \\
1 & 9 & 40,64 & 2350 \\
1 & 10 & 30,14 & 1050 \\
\hline SubTotal & & 37,83 & 1735 \\
\hline
\end{tabular}


Tabela 6 - Continuação.

\begin{tabular}{|c|c|c|c|}
\hline PARCELA & SUBPARCELA & ÁREA BASAL(m2/ha) & DENSIDADE(n/ha) \\
\hline 2 & 1 & 25,18 & 2150 \\
\hline 2 & 2 & 24,22 & 1800 \\
\hline 2 & 3 & 18,18 & 2050 \\
\hline 2 & 4 & 31,66 & 2550 \\
\hline 2 & 5 & 28,33 & 1550 \\
\hline 2 & 6 & 31,48 & 1600 \\
\hline 2 & 7 & 36,51 & 1300 \\
\hline 2 & 8 & 40,03 & 1650 \\
\hline 2 & 9 & 40,47 & 1900 \\
\hline 2 & 10 & 28,02 & 2000 \\
\hline SubTotal & & 30,41 & 1855 \\
\hline 3 & 1 & 36,34 & 2400 \\
\hline 3 & 2 & 43,97 & 2300 \\
\hline 3 & 3 & 44,11 & 1450 \\
\hline 3 & 4 & 53,07 & 1900 \\
\hline 3 & 5 & 43,26 & 2050 \\
\hline 3 & 6 & 54,44 & 1650 \\
\hline 3 & 7 & 24,34 & 1200 \\
\hline 3 & 8 & 18,27 & 1250 \\
\hline 3 & 9 & 23,56 & 1050 \\
\hline 3 & 10 & 33,44 & 1450 \\
\hline SubTotal & & 37,48 & 1670 \\
\hline 4 & 1 & 42,16 & 1850 \\
\hline 4 & 2 & 42,33 & 1450 \\
\hline 4 & 3 & 41,82 & 1700 \\
\hline 4 & 4 & 34,81 & 1850 \\
\hline 4 & 5 & 34,59 & 1650 \\
\hline 4 & 6 & 36,08 & 2400 \\
\hline 4 & 7 & 36,03 & 1950 \\
\hline 4 & 8 & 31,20 & 2050 \\
\hline 4 & 9 & 35,88 & 2200 \\
\hline 4 & 10 & 26,16 & 1700 \\
\hline SubTotal & & 36,10 & 1880 \\
\hline 5 & 1 & 45,88 & 1350 \\
\hline 5 & 2 & 17,49 & 1150 \\
\hline 5 & 3 & 28,42 & 1500 \\
\hline 5 & 4 & 40,09 & 2600 \\
\hline 5 & 5 & 13,85 & 1550 \\
\hline 5 & 6 & 45,56 & 1200 \\
\hline 5 & 7 & 24,54 & 1250 \\
\hline 5 & 8 & 31,08 & 1450 \\
\hline 5 & 9 & 55,81 & 650 \\
\hline 5 & 10 & 18,07 & 150 \\
\hline SubTotal & & 32,08 & 1285 \\
\hline TOTAIS & & 34,97 & 1685 \\
\hline
\end{tabular}


A Tabela 7 contem o tamanho e número de parcelas $\left(r^{\prime}\right)$ em função da área basal e densidade.

TABELA - 7 Tamanho e número de parcelas ( $\left.r^{\prime}\right)$ em função da área basal e densidade no Parque Estadual de Carlos Botelho (SP), para uma relação de custo $f=1$.

\begin{tabular}{lllll}
\hline Parâmetro & $\rho$ & $k^{\prime}$ & Tamanho & $r^{\prime}$ \\
\hline Área Basal & $-0,0254$ & - & - & - \\
Densidade & 0,1366 & $2,51 \cong 3,0$ & $10 \times 60 \mathrm{~m}$ & 14 \\
\hline
\end{tabular}

Teoricamente tem-se que quanto mais próximo de 0 (zero) estiver o valor de $\rho$, maior variação ocorre dentro das parcelas, portanto maior deverá ser o tamanho das parcelas utilizadas.

Quando o valor de $\rho$ é negativo não se pode determinar um valor para $\mathbf{k}^{\prime}$ (indefinido). Isto ocorre quando as variações dentro das parcelas são, ainda maiores, como foi o caso da estimativa de $\rho$ para a área basal $(\rho=-0,0254)$. Neste caso o valor de $k^{\prime}$ a ser considerado deverá ser o maior possível, superior a maior área definida neste trabalho $\left(2000 \mathrm{~m}^{2}\right)$.

As unidades amostrais podem apresentar variações internas diferentes entre si, pois por serem parcelas retangulares $(10 \mathrm{~m} \times 200 \mathrm{~m}$ ) tendem a abranger um gradiente maior.

Para a estimativa de densidade populacional, como o valor de $\rho$ foi positivo $(0,1366)$, o resultado encontrado para $k^{\prime}$ foi igual a 3 e para $\mathbf{r}^{\mathbf{0}}$ foi igual a 14. Esses resultados demonstram que para densidade, 
o tamanho de parcela de $10 \mathrm{~m} \times 60 \mathrm{~m}$ com 14 repetições seriam mais convenientes, para o local do estudo.

Com a redução do tamanho da parcela de $k=10$ para $k^{\prime}=3 \mathrm{e}$ aumento no número de parcelas de $r=5$ para $r=14$, a estimativa de variância da média que era de 4,59 passa para 3,12, ou seja, conseguese uma redução no erro padrão da média em tomo de $17,54 \%$, sem prejuizo dos custos de amostragem (para se estimar o parâmetro densidade de árvores na comunidade arbórea com DAP $\geq 5 \mathrm{~cm}$ ). Tais resultados podem ser interpretados como sendo devido às variações entre parcelas, que são maiores que as variações dentro parcelas, o que justifica a redução no tamanho e o aumento no número de parcelas.

Vale ressaltar que para cada tipo de vegetação e, dependendo dos objetivos do estudo, da precisão desejada, além dos custos e tempo dispendidos (Higuchi et al.1982; Couto 1984; Scolforo et al. 1993) que devem ser levados em conta, o tamanho, a forma e o número de parcelas podem variar consideravelmente. Neste sentido o uso do coeficiente de correlação intraclasse mostra-se adequado para as condições apresentadas.

\subsubsection{Estimativas para algumas espécies a partir da densidade}

Para cada uma das cinco unidades amostrais, contendo 10 subparcelas cada uma e de acordo com a metodologia, calculou-se a estimativa de $\rho$ para as árvores mortas e algumas das principais espécies da área de estudo, em função de sua densidade. Os resultados são apresentados na Tabela 8. 
TABELA 8 - Estimativas do tamanho e número de parcelas para árvores mortas e algumas das principais espécies da área, para uma relação de custo $f=1$.

\begin{tabular}{lccccc}
\hline ESPÉCIE & $\rho$ & $\begin{array}{c}\text { Tamanho } \\
\text { da } \\
\text { Parcela } \\
\mathbf{k}\end{array}$ & $\begin{array}{c}\text { Número } \\
\text { de } \\
\text { Parcelas } \\
\mathbf{r}^{\circ}\end{array}$ & $\begin{array}{c}\text { Dimensōes } \\
\text { das } \\
\text { parcelas } \\
(\mathbf{m})\end{array}$ & $\begin{array}{c}\text { Redução } \\
\text { no erro } \\
\text { padrăo (\%) } \\
(*)\end{array}$ \\
\hline Rapanea femuginea & 0,064 & 4 & 11 & $10 \times 80$ & 26,26 \\
Roupala brasiliensis & 0,046 & 5 & 10 & $10 \times 100$ & 20,02 \\
Thbouchina pulchra & 0,004 & 16 & 3 & $10 \times 320$ & 2,350 \\
Mortas & 0,022 & 7 & 7 & $10 \times 140$ & 9,500 \\
Hyeronima alchomeoides & 0,169 & 2 & 17 & $10 \times 40$ & 50,00 \\
Solanum inaequale & $-0,017$ & - & - & - & - \\
Jacaranda puberula & $-0,002$ & - & - & - & - \\
Cabralea canjerana & $-0,018$ & - & - & - & - \\
Euterpe edulis & $-0,039$ & - & - & - & - \\
\hline
\end{tabular}

$\left(^{*}\right)$ - em relação ao tamanho $10 \times 200\left(2000 \mathrm{~m}^{2}\right)$.

No item 4.2.1 conclui-se que um tamanho de $10 \times 60 \mathrm{~m}$ otimiza o desenho amostral inicial para a comunidade, no entanto esse mesmo tamanho de parcelas não pode ser assumido como um tamanho adequado para uma análise por espécies na comunidade amostrada.

Os resultados mostram que mesmo para as espécies mais comuns de uma área amostral de 1 ha os tamanhos e número de parcelas para cada espécie são muito variáveis. Isso pode ser uma consideração importante para responder o porquê do tamanho de parcelas para estudo de florestas tropicais ser um problema não resolvido e porque fica dificil uma padronização de tamanho de parcelas.

Mas por quê as espécies se comportam desta maneira? À grande diversidade de espécies segue-se também uma diversidade de 
padrões de regeneração para as espécies da floresta tropical, influenciando profundamente no padrão espacial das espécies na floresta. Estas variações na distribuição dos indivíduos dentro das parcelas podem ser tão grandes que o valor de $\rho$ é negativo (Tabela 8 ).

As Tabelas 9 a 17, abaixo dão uma idéia da distribuição das espécies na área, à época da amostragem:

TABELA 9 - Distribuição esquemática de individuos de Rapanea ferruginea.

\begin{tabular}{|l|}
\hline SUBPARCELAS \\
\hline SP1 \\
\hline SP2 \\
\hline SP3 \\
\hline SP4 \\
\hline SP5 \\
\hline SP6 \\
\hline SP7 \\
\hline SP8 \\
\hline SP9 \\
\hline SP10 \\
\hline
\end{tabular}

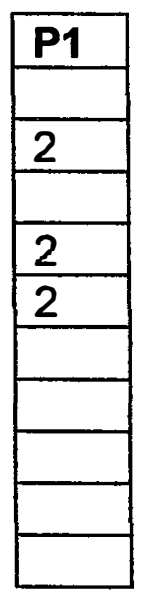

PARCELAS

\begin{tabular}{|l|}
\hline P2 \\
\hline 3 \\
\hline 5 \\
\hline 4 \\
\hline 10 \\
\hline 1 \\
\hline 1 \\
\hline \\
\hline \\
\hline \\
\hline \\
\hline
\end{tabular}

\begin{tabular}{|l|}
\hline P4 \\
\hline 1 \\
\hline \\
\hline 1 \\
\hline \\
\hline 1 \\
\hline 3 \\
\hline \\
\hline
\end{tabular}

\begin{tabular}{|l|}
\hline P5 \\
\hline \\
\hline 1 \\
\hline 1 \\
\hline \\
\hline \\
\hline \\
\hline \\
\hline \\
\hline
\end{tabular}

TABELA 10 - Distribuição esquemática de indivíduos de Roupala brasiliensis.

\begin{tabular}{|l|}
\hline SUBPARCELAS \\
\hline SP1 \\
\hline SP2 \\
\hline SP3 \\
\hline SP4 \\
\hline SP5 \\
\hline SP6 \\
\hline SP7 \\
\hline SP8 \\
\hline SP9 \\
\hline SP10 \\
\hline
\end{tabular}

\begin{tabular}{|l|}
\hline $\mathbf{P 1}$ \\
\hline 1 \\
\hline \\
\hline 1 \\
\hline 2 \\
\hline 1 \\
\hline 3 \\
\hline 1 \\
\hline 2 \\
\hline
\end{tabular}

PARCELAS

\begin{tabular}{|l|}
\hline $\mathbf{P 2}$ \\
\hline \\
\hline \\
\hline \\
\hline 2 \\
\hline 1 \\
\hline 1 \\
\hline 1 \\
\hline \\
\hline
\end{tabular}

\begin{tabular}{|l|}
\hline P3 \\
\hline 1 \\
\hline 1 \\
\hline \\
\hline \\
\hline \\
\hline 3 \\
\hline 3 \\
\hline
\end{tabular}

\begin{tabular}{|l|}
\hline P4 \\
\hline \\
\hline 3 \\
\hline 1 \\
\hline 3 \\
\hline 2 \\
\hline 5 \\
\hline 2 \\
\hline 5 \\
\hline
\end{tabular}

\begin{tabular}{|l|}
\hline P5 \\
\hline \\
\hline \\
\hline 6 \\
\hline 1 \\
\hline 2 \\
\hline 1 \\
\hline \\
\hline \\
\hline
\end{tabular}


TABELA 11 - Distribuição esquemática de indivíduos de Tibouchina

\begin{tabular}{|c|c|}
\hline SUBPARCELAS & paicina \\
\hline & P1 \\
\hline SP1 & 2 \\
\hline SP2 & 1 \\
\hline SP3 & \\
\hline SP4 & \\
\hline SP5 & \\
\hline SP6 & \\
\hline SP7 & \\
\hline SP8 & 3 \\
\hline SP9 & 1 \\
\hline SP10 & \\
\hline
\end{tabular}

PARCELAS

\begin{tabular}{|l|}
\hline $\mathbf{P 2}$ \\
\hline 10 \\
\hline 9 \\
\hline 8 \\
\hline 4 \\
\hline 1 \\
\hline 1 \\
\hline \\
\hline \\
\hline \\
\hline \\
\hline
\end{tabular}

\begin{tabular}{|l|}
\hline $\mathbf{P 4}$ \\
\hline 1 \\
\hline 3 \\
\hline 6 \\
\hline 4 \\
\hline 5 \\
\hline 2 \\
\hline
\end{tabular}

\begin{tabular}{|l|}
\hline P5 \\
\hline 1 \\
\hline 4 \\
\hline 4 \\
\hline 1 \\
\hline \\
\hline \\
\hline \\
\hline
\end{tabular}

TABELA 12 - Distribuição esquemática de indivíduos de árvores Mortas.

\begin{tabular}{|l|}
\hline SUBPARCELAS \\
\hline SP1 \\
\hline SP2 \\
\hline SP3 \\
\hline SP4 \\
\hline SP5 \\
\hline SP6 \\
\hline SP7 \\
\hline SP8 \\
\hline SP9 \\
\hline SP10 \\
\hline
\end{tabular}

\begin{tabular}{|l|}
\hline $\mathbf{P 1}$ \\
\hline 2 \\
\hline 1 \\
\hline 1 \\
\hline 1 \\
\hline 2 \\
\hline 2 \\
\hline 5 \\
\hline 3 \\
\hline
\end{tabular}

\begin{tabular}{|l|}
\hline $\mathbf{P 2}$ \\
\hline 4 \\
\hline 1 \\
\hline 4 \\
\hline 1 \\
\hline 3 \\
\hline 3 \\
\hline 2 \\
\hline 5 \\
\hline 3 \\
\hline
\end{tabular}

\begin{tabular}{|l|}
\hline $\mathbf{P 3}$ \\
\hline 5 \\
\hline 1 \\
\hline 6 \\
\hline 1 \\
\hline 1 \\
\hline 2 \\
\hline 1 \\
\hline 3 \\
\hline
\end{tabular}

\begin{tabular}{|l|}
\hline $\mathbf{P 4}$ \\
\hline 2 \\
\hline 1 \\
\hline 1 \\
\hline 3 \\
\hline 1 \\
\hline 1 \\
\hline 3 \\
\hline 1 \\
\hline
\end{tabular}

\begin{tabular}{|l|}
\hline P5 \\
\hline 1 \\
\hline 3 \\
\hline 2 \\
\hline 1 \\
\hline 2 \\
\hline 1 \\
\hline
\end{tabular}


TABELA 13 - Distribuição esquemática de indivíduos de Hyeronima alchorneoides.

\begin{tabular}{|l|}
\hline SUBPARCELAS \\
\hline SP1 \\
\hline SP2 \\
\hline SP3 \\
\hline SP4 \\
\hline SP5 \\
\hline SP6 \\
\hline SP7 \\
\hline SP8 \\
\hline SP9 \\
\hline SP10 \\
\hline
\end{tabular}
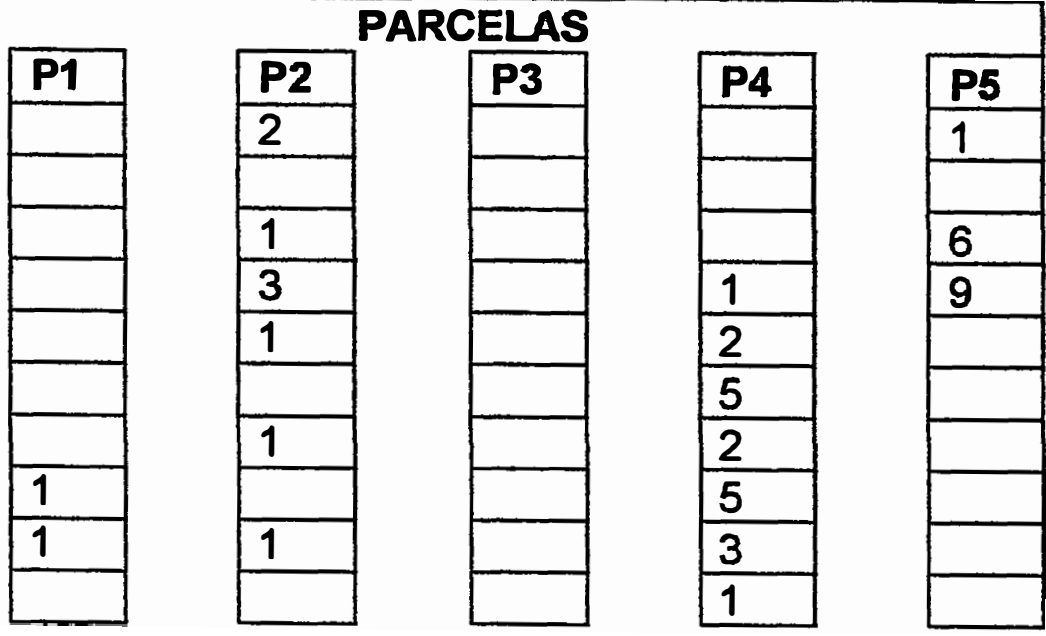

TABELA 14 - Distribuição esquemática de indivíduos de Solanum inaequale.

\begin{tabular}{|l|}
\hline SUBPARCELAS \\
\hline SP1 \\
\hline SP2 \\
\hline SP3 \\
\hline SP4 \\
\hline SP5 \\
\hline SP6 \\
\hline SP7 \\
\hline SP8 \\
\hline SP9 \\
\hline SP10 \\
\hline
\end{tabular}

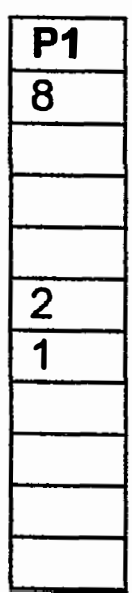

\begin{tabular}{|l|}
\hline P2 \\
\hline 1 \\
\hline 3 \\
\hline 1 \\
\hline 4 \\
\hline 5 \\
\hline 5 \\
\hline 3 \\
\hline 2 \\
\hline 9 \\
\hline 8 \\
\hline
\end{tabular}

PARCELAS
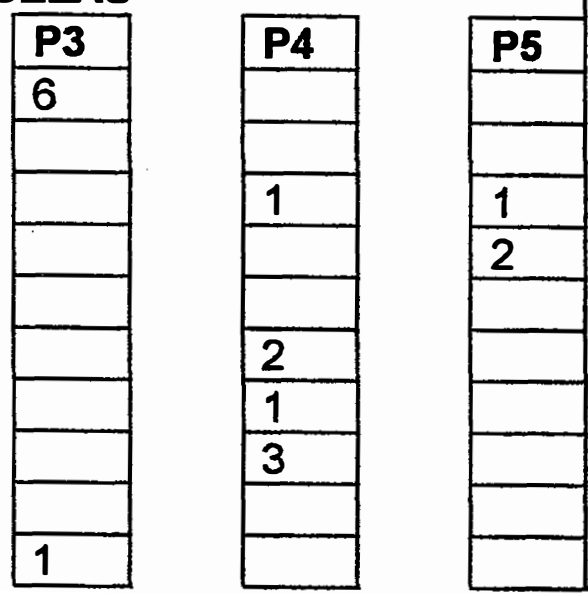
TABELA 15 - Distribuição esquemática de indivíduos de Cabralea canjerana.

\begin{tabular}{|l|}
\hline SUBPARCELAS \\
\hline SP1 \\
\hline SP2 \\
\hline SP3 \\
\hline SP4 \\
\hline SP5 \\
\hline SP6 \\
\hline SP7 \\
\hline SP8 \\
\hline SP9 \\
\hline SP10 \\
\hline
\end{tabular}

\begin{tabular}{|l|}
\hline $\mathbf{P 1}$ \\
\hline 1 \\
\hline 2 \\
\hline \\
\hline \\
\hline 1 \\
\hline 1 \\
\hline
\end{tabular}

PARCELAS

\begin{tabular}{|l|}
\hline $\mathbf{P 2}$ \\
\hline \\
\hline 1 \\
\hline 1 \\
\hline 1 \\
\hline 1 \\
\hline 1 \\
\hline
\end{tabular}

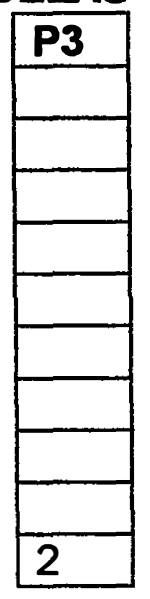

\begin{tabular}{|l|}
\hline $\mathbf{P 4}$ \\
\hline \\
\hline 1 \\
\hline 1 \\
\hline 2 \\
\hline 1 \\
\hline 3 \\
\hline 5 \\
\hline
\end{tabular}

\begin{tabular}{|l|}
\hline P5 \\
\hline \\
\hline 4 \\
\hline 1 \\
\hline 1 \\
\hline 1 \\
\hline \\
\hline
\end{tabular}

TABELA 16 - Distribuição esquemática de indivíduos de Euterpe edulis.

\begin{tabular}{|l|}
\hline SUBPARCELAS \\
\hline SP1 \\
\hline SP2 \\
\hline SP3 \\
\hline SP4 \\
\hline SP5 \\
\hline SP6 \\
\hline SP7 \\
\hline SP8 \\
\hline SP9 \\
\hline SP10 \\
\hline
\end{tabular}

\begin{tabular}{|l|}
\hline $\mathbf{P 1}$ \\
\hline 1 \\
\hline 4 \\
\hline 2 \\
\hline 1 \\
\hline 1 \\
\hline 2 \\
\hline 1 \\
\hline \\
\hline 2 \\
\hline
\end{tabular}
PARCELAS

\begin{tabular}{|l|}
\hline $\mathbf{P 2}$ \\
\hline 1 \\
\hline 1 \\
\hline 1 \\
\hline \\
\hline \\
\hline \\
\hline \\
\hline
\end{tabular}

\begin{tabular}{|l|}
\hline $\mathbf{P 3}$ \\
\hline 2 \\
\hline 3 \\
\hline 2 \\
\hline 2 \\
\hline 1 \\
\hline 2 \\
\hline 1 \\
\hline
\end{tabular}

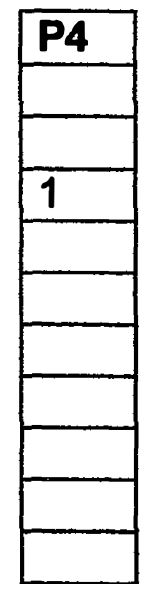

\begin{tabular}{|l|}
\hline P5 \\
\hline 1 \\
\hline 2 \\
\hline 1 \\
\hline 4 \\
\hline 2 \\
\hline 1 \\
\hline 1 \\
\hline
\end{tabular}


TABELA 17 - Distribuição esquemática de indivíduos de Jacaranda puberula.

\begin{tabular}{|c|c|c|c|c|c|}
\hline SUBPARCELAS & \multicolumn{4}{|c|}{ PARCELAS } & \\
\hline & P1 & P2 & P3 & $\overline{\text { P4 }}$ & P5 \\
\hline SP1 & & 2 & 1 & & \\
\hline SP2 & & 5 & & & \\
\hline SP3 & & & & & \\
\hline SP4 & & 2 & & 1 & \\
\hline SP5 & & & & & \\
\hline SP6 & & & & 5 & \\
\hline SP7 & & & & 1 & \\
\hline SP8 & 4 & 1 & & 1 & \\
\hline SP9 & 5 & & & 1 & \\
\hline SP10 & 2 & & & & \\
\hline
\end{tabular}

Esse padrão assume basicamente três formas: aleatório, agrupado ou regular (Crawley, 1986), mas diversas combinações destes padrões podem ainda ser obtidas, dependendo da escala do estudo. Uma análise do padrão espacial neste estudo teria pouco sentido devido à pequena escala espacial. Leão (1990) mostra que os métodos para determinação de padrões, que são baseados em indices, podem apresentar resultados discordantes, além de sofrer influências de variações dos locais, do tamanho da amostra e do tamanho da área.

Alguns trabalhos mostram que a estrutura populacional de espécies podem ser variáveis à curtas distâncias (Hubbell \& Foster, 1987; Poorter et al., 1996).

Sabe-se também que os padrões espaciais das espécies podem ser variáveis no tempo. Por exemplo a espécie Tibouchina pulchra domina as florestas secundárias da encosta atlântica (Tabarelli et al., 1994), entretanto apresenta baixa densidade nas florestas maduras, ocorrendo basicamente nas áreas onde há um aumento na intensidade 
luminosa. O contrário ocorre com a espécie Euterpe edulis, que relativamente apresenta maior densidade nas florestas pluviais da encosta atlântica em estádios sucessionais avançados.

Para dificultar ainda mais qualquer conclusão observa-se em diferentes estudos realizados, desde as matas ciliares do interior, às florestas semi-decíduas e às florestas da encosta atlântica (Durigan e Leitão Filho, 1995; Custódio Filho et al., 1994; Bertoni, 1984; Negreiros et al., 1995; Tabarelli et al., 1994; Mantovani, 1993; Silva, 1989; Negreiros, 1982 e Silva, 1980), que as mesmas espécies podem variar sua densidade de indivíduos em função das características de cada ambiente. As espécies responderiam à essa heterogeneidade ambiental com a plasticidade fenotípica (Turkington \& Aarssen, 1984).

Como então seria resolvida a questão da amostragem de espécies arbóreas na floresta tropical? Na realidade uma estimativa da densidade populacional de qualquer espécie pode ser obtida a partir de qualquer tamanho e forma de parcelas, entretanto, variando significativamente, o custo e precisão da amostragem (Husch et al., 1971). Mas pelos resultados encontrados dificilmente um só tamanho poderia ser adequado a todas as espécies, principalmente considerandose as espécies de baixa densidade populacional, das quais pouco ou nada pode ser dito em estudos de pequena escala.

Os estudos de vegetação, visando amostrar um grande número de espécies na comunidade tem sua grande contribuição no conhecimento da florística e da diversidade da floresta atlântica e ainda podem ser muito úteis nas análises de gradientes e padrões gerais da comunidade. Entretanto tomam-se muito dispendiosos e limitados quando 
tentam responder aos padrões a nível de espécie, pois a maioria das espécies da floresta tropical apresenta baixa densidade e necessita de uma metodologia diferenciada de estudo.

Um novo conceito para estudos de florestas tropicais e de importância muito maior para uso na conservação e manejo da floresta deve prever estudos populacionais. Como as populações reagem à heterogeneidade ambiental e aos distúrbios mais freqüentes da floresta (Swaine, 1989). Nesse sentido o melhor planejamento da amostragem populacional pode ser obtido com um conhecimento prévio sobre a ecologia da espécie no ecossistema: sua forma de dispersão, habitats de regeneração, padrão espacial, distribuição etária, entre outros. 


\section{CONCLUSÃO}

No estudo sobre o tamanho e número de parcelas para uma mata secundária no Parque Estadual de Carlos Botelho (SP) foi constatado que pode-se aumentar a precisão do levantamento com a otimização do desenho inicial proposto, ou seja, parcelas menores e mais amplamente distribuídas sobre a área captam melhor a variação da floresta (para o parâmetro densidade) do que parcelas de maior comprimento. Já para o parâmetro área basal não foi possível otimizar o tamanho, mas as parcelas mais alongadas devem ser mais eficientes já que ocorrem maiores variações ao longo dos gradientes.

O cálculo do tamanho de parcelas a nível de espécies mostra que ocorrem grandes variações entre elas. Ao se admitir um tamanho único de parcelas para a análise das várias espécies da comunidade deve se ter em mente os erros amostrais que estão sendo envolvidos para a maioria delas, principalmente as de baixa densidade populacional, em amostras de 1 ha.

As espécies dominantes se constituem nas comumente encontradas em diversos trechos da floresta atlântica secundária no estado de São Paulo, sendo constituintes dos estádios iniciais de sucessão. Das 14 espécies de maior IVI notou-se que duas (Eugenia brasiliensis e Nectandra sp2) atingiram suas posições devido a indivíduos de grande porte, enquanto que as outras 12 tiveram maior influência da alta densidade relativa.

O padrão de distribuição diamétrica mais comumente encontrado nas espécies analisadas se assemelha ao "J invertido", 
indicando distribuição contínua e decrescente a partir das menores classes diamétricas, esse padrão é típico de espécies tolerantes.

A distribuição de forma " $\mathrm{J}$ " invertido caracteriza uma formação heterogênea, ineqüiânea e em fase sucessional avançada, por isso a variação encontrada, pois a última perturbação ocorrida na área estudada se deu há 57 anos, tendo sofrido intensa intervenção antes deste período. 


\section{REFERÊNCIAS BIBLIOGRÁFICAS}

BAITELLO, J.B.; AGUIAR, O.T. de; ROCHA, F.T.; PASTORE, J.A.; ESTEVEZ, R. Florística e fitossociologia do estrato arbóreo de um trecho da serra da Cantareira (Núcleo Pinheirinho-SP). Revista do Instituto Florestal, v.4, n.1, p.291-7, mar. 1992.

BARROS, P.L.C. de. Estudo fitossociológico de uma floresta tropical úmida no Planalto de Curuá-Una, Amazônia brasileira. Curitiba, 1986. 158p. Tese (Doutorado) - Universidade Federal do Paraná.

BATISTA, J.L.F. A função Weibull como modelo para a distribuição de diâmetros de espécies arbóreas tropicais. Piracicaba, 1989. 116p. Dissertaçāo (M.S.) - Escola Superior de Agricultura "Luiz de Queiroz", Universidade de São Paulo.

BERTONI, J.E.A. Composição florística e estrutura fitossociológica de uma floresta do interior do Estado de São Paulo: Reserva Estadual de Porto Ferreira. Campinas, 1984. 196p. Dissertação (M.S.) Universidade de Campinas.

BRAUN-BLANQUET, J. Plant Sociology: the study of plant communities. New York and London: McGraw-Hill Book Company, Inc. First Ed. 1932. p.26-59.

CAIN, S.A.; CASTRO, G.N. de O.; PIRES, J.M.; SILVA, N.T. da. Applications of some phytosociological techniques to Brazilian rain forest; 2-composition and structure of terra firme forest of Mucambo, Belém, Pará. American Journal of Botany, v.43, p.915-28, 1956.

CARVALHO, P.E.R. Espécies florestais brasileiras: recomendaçōes silviculturais, potencialidades e uso da madeira. Colombo: Embrapa-CNPF, Brasilia: Embrapa-SPI, 1994. 640p.

CAVASSAN, O. et al. Fitossociologia da vegetação arbórea da Reserva Estadual de Bauru, Estado de São Paulo. Revista Brasileira de Botânica, v.7, n.2, p.91-106, 1984.

CONSELHO ESTADUAL DO MEIO AMBIENTE. Áreas Naturais do Estado de São Paulo. 1985. 16p.

COSTA NETO, J. B. (Coord.) Plano de Ação Emergencial: Implantação e manejo de unidades de conservação. São Paulo: SMA/IF-DRPE/IF, 1993/94. 78p. 
COSTA, L.G.S. Estrutura e dinâmica de trecho de mata mesófila semidecídua, na Estação Ecológica de Ibicatú, Piracicaba, SP. São Paulo, 1992. Dissertação (M.S.) - Instituto de Biociências, Universidade de São Paulo.

COUTO, H.T.Z. do. Sistemas Integrados de Levantamentos Florestais. In: SIMPÓSIO SOBRE INVENTÁRIO FLORESTAL, 2, Piracicaba, 1984. Anais. Piracicaba: ESALQ/IPEF, 1984. p.121-7.

CRAWLEY, M.J. The structure of Plant communities. In: CRAWLEY, M. J. Plant Ecology. Oxford: Blackwell, 1986. p.1-50.

CURTIS, J.T. \& McINTOSH, R.P. An upland forest continuum in the prairie-forest border region of Wisconsin. Ecology, v.32, n.3, p.476-96, 1951.

CUSTODIO FILHO, A.; NEGREIROS, O.C. de; DIAS, A.C. \& FRANCO, G.A.D.C. Composição florística do estrato arbóreo do Parque Estadual de Carlos Botelho, S.P. Revista do Instituto Florestal, v.4, n.1, p.18491, mar. 1992.

CUSTÓDIO FILHO, A.; FRANCO, G.A.D.C.; NEGREIROS, O.C. de; MARIANO, G.; GIANNOTTI, E.; DIAS, A.C. Composição florística da vegetação arbórea da floresta mesófila semidecídua da Estação Ecológica de Ibicatú, Piracicaba (SP). Revista do Instituto Florestal, v.6 (único), p.99-111, 1994.

DE VUONO, Y.S. Fitossociologia do estrato arbóreo da floresta da reserva do Instituto de Botânica. São Paulo. São Paulo, 1985. 213p. Tese (Doutorado) - Instituto de Biociências, Universidade de São Paulo.

DIAS, A.C.; NEGREIROS, O.C. de ; VEIGA, A. de A. \& COUTO, H.T.Z. do. Um cotejo entre métodos para levantamento fitossociológico, no Núcleo Sete Barras do Parque Estadual de Carlos Botelho, IF/SP. Boletim Técnico do Instituto Florestal, v.40A, n.2, p.463-80, 1986.

DIAS, A.C. Estrutura e diversidade do componente arbóreo e a regeneração do palmito (Euterpe edulis) em um trecho de mata secundária, no Parque Estadual de Carlos Botelho, SP. Piracicaba, 1993. 126p. Dissertação (M.S.) - Escola Superior de Agricultura "Luiz de Queiroz", Universidade de São Paulo.

DOMINGUES, E.N.; SILVA, D.A. Geomorfologia do Parque Estadual de Carlos Botelho. Boletim Técnico do Instituto Florestal, v.42, p.71105, 1988. 
DURIGAN, G.; LEITÃO FILHO, H.F. Florística e fitossociologia de matas ciliares do oeste paulista. Revista do Instituto Florestal, v.7, n.2, p.197-239, 1995.

FUNDAÇÃO INSTITUTO BRASILEIRO DE GEOGRAFIA E ESTATíSTICA. Rio de Janeiro: IBGE. Mapa da Vegetação do Brasil. 1988.

FUNDAÇÃO SOS MATA ATLÂNTICA. Dossiê Mata Atlântica, 107p. 1992.

HEINSDIJK, D.C.; CAMPOS, J.C.C. Programa de manejo das florestas de produção estaduais. Silvicultura em São Paulo, v.6 (único), p.365405, 1967.

HIGUCHI, N.; SANTOS, J. dos; JARDIM, F.C.S. Tamanho de parcela amostral para inventários florestais. Acta Amazónica, v.12, n.1, p.91103, 1982.

HUBELL, S.P.; FOSTER, R.B. La estructura espacial en gran escala de un bosque neotropical. Revista de Biologia Tropical, v.35, (supl. 1), p.7-22, 1987.

HUECK, K. As florestas da América do Sul: ecologia, composição e importância econômica. São Paulo: Ed. U.F. Brasília/Ed. Polígono S.A. 1972, p.149-68.

HUSCH, B.; MUELLER, C.I.; BEERS, T.W. Forest Mensuration. New York: Ronald Press, 1971, 410p.

HUTCHINGS, M.J. The structure of plant populations. In: Plant Ecology. Oxford: Ed. Michael J. Crawley Blackwell Scientific Publications. 1986, p.97-111.

JARDIM, F.C.S.; HOSOKAWA, R.T. Estrutura da floresta equatorial úmida da estação experimental de silvicultura tropical do INPA. Acta Amazônica, v.16/17, (único), p.411-507, 1986/87.

JESUS, R.M.; ROLIM, S.G.; GARCIA, A. Estudo do tamanho de parcelas para amostragem da vegetação na floresta atlântica de Linhares (ES). (não publicado).

JOLY, A.B. Conheça a vegetação brasileira. São Paulo: EDUSP, 1970. $181 \mathrm{p}$.

KRONKA, F.J.N.; MATSUKUMA, C.K.; NALON, M.A.; DEL CALI, I.H.; ROSSI, M.; MATTOS, I.F.A.; SHIN-IKE, M.S.; PONTINHAS, A.A.S. 
Inventário florestal do Estado de São Paulo. São Paulo: Instituto Florestal. CINP, 1993. 199p.

LAMPRECHT, H. Ensayo sobre la estructura floristica de la parte suroriental del Bosque Universitario "El Caimital", Estado Barinas. Revista Forestal Venezolana v.6, n.10/11), p.77-119, 1964.

LAMPRECHT, H. Silvicultura nos trópicos: ecossistemas florestais e respectivas espécies arbóreas - possibilidades e métodos de aproveitamento sustentado. Eschbom: Cooperação Técnica República Federal da Alemanha, 1990. 343p.

LEÃO, N.V.M. Disseminação de sementes e distribuição espacial de espécies arbóreas na Floresta Nacional do Tapajós, Santarém, Pará. Piracicaba, 1990. 129p. Dissertação (M.S.) - Escola Superior de Agricultura "Luiz de Queiroz", Universidade de São Paulo.

LEITÃO FILHO, H.F. (Org.). Ecologia da Mata Atlântica em Cubatão. Campinas, Editora Unesp e Editora da Universidade de Campinas. 1993. 184p.

LEITÃO FILHO, H.F. Aspectos taxonômicos das florestas do Estado de São Paulo. Silvicultura em São Paulo, v.16A, P.1, p.197-206, 1982.

LORENZI, H. Árvores brasileiras: Manual de identificação e cultivo de plantas arbóreas nativas do Brasil. Nova Odessa: Editora Plantarum, 1992. 352p.

MACHADO, S. do A.; ROSOT, N.C.; FIGUEIREDO FILHO, A. Distribuição diamétrica em uma floresta tropical úmida da Amazônia Brasileira. Silvicultura em São Paulo, V.16A, P1, p.399-411, 1982.

MANTOVANI, W. Estrutura e dinâmica da Floresta Atlântica na Juréia, Iguape- SP. São Paulo, 1993.126p. Tese (Livre Docência) - Instituto de Biociências, Universidade de São Paulo.

MARTINEZ-RAMOS, M.C. Ciclos vitales de los arboles tropicales y regeneracion natural de las selvas altas perenifolias. In: Investigaciones sobre primeira regeneracion de selvas altas en Vera Cruz, México: Ed. Alhambra Mexicana. SA de CV, 1985. v.II, p.191-239.

MARTINS, F.R. O método de quadrantes e a fitossociologia de uma floresta residual do interior do Estado de São Paulo: Parque Estadual de Vassununga. São Paulo, 1979. 239p. Tese (Doutorado) - Instituto de Biociências, Universidade de São Paulo. 
MARTINS, F.R. Estrutura de uma floresta mesófila. Campinas: Editora da UNICAMP, 1991, 246p.

MUELLER-DOMBOIS, D.; ELLENBERG, H. Aims and methods of vegetation ecology. New York: John Willey, 1974. 547p.

NEGREIROS, O.C. de. Características fitossociológicas de uma comunidade de floresta latifoliada pluviosa tropical visando ao manejo de palmito Euterpe edulis Mart. Piracicaba, 1982, 104p. Dissertação (M.S.) - Escola Superior de Agricultura "Luiz de Queiroz", Universidade de São Paulo.

NEGREIROS, O.C.; CUSTODIO FILHO,A.; DIAS, A.C.; FRANCO, G.A.D.C.; COUTO, H.T.Z. do; VIEIRA, M.G.L.; MOURA NETTO, B.V. de. Análise -estrutural de um trecho de floresta pluvial tropical, Parque Estadual de Carlos Botelho, Núcleo Sete Barras (SP-Brasil). Revista do Instituto Florestal, v.7, n.1, p.1-33,1995.

O'BRIEN, M.J.P.; O'BRIEN, C.M. Ecologia e modelamento de florestas tropicais. Belém: FCAP, 1995.

OLIVEIRA FILHO, L.C. Inventário nas formaçōes florestais e campestres. In: Manual Técnico da vegetação brasileira. Rio de Janeiro: IBGE, 1992. p.39-54

PAGANO, S.N.; LEITÃO FILHO, H.F.; SHEPHERD, G.J. Estudo fitossociológico do estrato arbóreo em mata mesófila semidecídua, no Município de Rio Claro, Estado de São Paulo. Revista Brasileira de Botânica, v.10, p.49-61, 1987.

PFEIFER, R.M.; CARVALHO, W.A.; SILVA, D.A. da; ROSSI, M.; MENDICINO, L.F. Levantamento semi-detalhado dos solos do Parque Estadual de Carlos Botelho, S.P. Boletim Técnico do Instituto Florestal, v.40, n.1, p.75-109, 1986.

PIELOU, E.C. Ecological diversity. New York: John Willey, 1975. 165p.

PIMENTEL-GOMES, F. O problema do tamanho das parcelas em experimentos com plantas arbóreas. Pesquisa Agropecuária Brasileira, v.19, n.12, p.1507-12, dez. 1984.

PIMENTEL-GOMES, F.; CHAVES, R. A amostragem ótima em inventário florestal. IPEF, v.38, p17-22, 1988.

PIMENTEL-GOMES, F.; COUTO,H.T.Z. do. O tamanho ótimo de parcela experimental para ensaios com eucaliptos. IPEF, v.31, p.75-7, 1985. 
POORTER, L.; BONGERS, F.; POMPAEY, R.S.A.R. van; KLERK, M. de Regeneration of canopy tree species at five sites in west African moist forest. Forest Ecology and Management, v.84, p.61-9, 1996.

QUEIRÓZ, W.T. Efeitos da variação estrutural em unidades amostrais na aplicação do processo de amostragem em conglomerados nas florestas do Planalto Tapajós. Curitiba, 1977. 125p. Dissertação (M.S.) - Universidade Federal do Paraná.

REITZ, R.; KLEIN, R.M.; REIS, A. Projeto Madeira de Santa Catarina. Sellowia, v.28, p.1-320, 1978.

REITZ, R.; KLEIN, R.M.; REIS, A. Projeto Madeira do Rio Grande do Sul. Sellowia, v.34/35, p.1-525, 1983.

RODRIGUES, R.R. Levantamento florístico e fitossociológico das matas da Serra do Japi, Jundiaí. Campinas, 1986. 198p. Dissertação (M.S.) Instituto de Biologia, Universidade de Campinas.

ROMARIZ, D.A. A vegetaçāo. In: Brasil, a terra e o homem. São Paulo: Ed. Nacional, v.1. 1964. 571p.

ROSOT, N.C.; MACHADO, S. do A.; FIGUEIREDO FILHO, A. Análise estrutural de uma floresta tropical como subsídio básico para elaboração de um plano de manejo florestal. Silvicultura em São Paulo, v.16A, P.1, p.468-90, 1982.

SANCHES, M. Florística e Fitossociologia da vegetação arbórea nas margens do rio Fazenda (Parque Estadual da Serra do Mar - Núcleo Picinguaba - Ubatuba/SP). Rio Claro, 1994. 75p. Dissertação (M.S.) Instituto de Biologia, Universidade Estadual Paulista.

SCOLFORO, J.R.S.; CHAVES, A.L.; MELO, J.M. de. Definição de tamanho de parcela para inventário florestal em Floresta Semidecídua Montana. In: CONGRESSO FLORESTAL BRASILEIRO, 7, Curitiba, 1993. Anais. São Paulo: SBS/SBEF, 1993. v.1, p.333-7.

SERRA FILHO, R.; CAVALI, A.C.; GUILHAUMON, J.R. et al. Levantamento da cobertura natural e reflorestamento no Estado de São Paulo. Boletim Técnico do Instituto Florestal, v.11, p.1-53, 1974.

SETZER, J. Contribuição para o estudo do clima do Estado de São Paulo. São Paulo: Escolas Profissionais Salesianas, 1946. 239p.

SILVA, A.F. Composição florística e estrutura de um trecho da mata atlântica de encosta no municipio de Ubatuba (SP). Campinas, 1980. 
153p. Dissertação (M.S.) - Instituto de Biologia, Universidade de Campinas.

SILVA, A.F. Composição florística e estrutura fitossociológica do estrato arbóreo da Reserva Florestal Augusto Ruschi, São José dos Campos, SP. Campinas, 1989. 162p. Tese (Doutorado) - Instituto de Biologia, Universidade de Campinas.

SILVA, F.C. Composição florística e estrutura fitossociológica da floresta tropical ombrófila da encosta atlântica, no município de Morretes (PR). Boletim de Pesquisa Florestal, v.18/19, p.31-49, 1989.

SILVA, J.N.M.; LOPES, J.C.A. Inventário florestal contínuo em florestas tropicais: a metodologia utilizada pela EMBRAPACPATU na Amazônia Brasileira. In: SIMPÓSIO SOBRE INVENTÁRIO FLORESTAL, 2, Piracicaba, 1984. Anais. Piracicaba: ESALQ/IPEF, 1984. p.65-79.

SIQUEIRA, M.F. Análise florística e ordenação de espécies arbóreas da mata atlântica através de dados binários. Campinas, 1994. 143p. Dissertação (M.S.) - Instituto de Botânica, Universidade de Campinas.

SPURR, S.H. Forest Inventory. The Ronald Press Company, 1952. 476p.

STEIN, W.I. Regeneration surveys and evaluation. In: Reforestation

Practices in Southwestern Oregon and Northern California, 15. p.346-82. 1993.

SWAINE, M.D. Population dynamics of tree species in tropical forests. In: L.B. HOLM-NIELSEN; I.C.NIELSEN; H. BALSLEV (Eds). Tropical forests: botanical, dynamics, speciation and diversity. London: Academic Press Limited, 1989, 380p.

TABARELLI, M.; VILLANI, J.P.; MANTOVANI, W. Estudo comparativo da vegetação de dois trechos de floresta secundária no Núcleo Santa Virgínia, Parque Estadual da Serra do Mar (SP). Revista do Instituto Florestal, v.6, (único), p.1-11, 1994.

TURKINGTON, R.; AARSSEN, L. W. Local-scale differentiation as a result of competitive interactions.. In: DIRZO, R. \& J. SARUKHÁN (eds). Perspectives on plant population ecology. Sunderland, 1984, p.10727.

VASCONCELOS, P.C.S. Fitossociologia de uma vegetação em sucessão secundária, no Vale do Paraíba, São Paulo. Viçosa, 1992. Dissertação (M.S.) - Universidade Federal de Viçosa. 
VELOSO, H. P.; KLEIN, R. M. As comunidades e associações vegetais da mata pluvial do sul do Brasil. Sellowia, v.20, p.53-126, 1968.

VENTURA, A. Problemas técnicos da silvicultura paulista. Silvicultura em Sảo Paulo, v.3, p.61-80, 1964.

VICTOR, M.A.M. A devastação florestal. São Paulo: SBS, 1975, 48p. 